\title{
MODELING REGIONAL RADIOCARBON TRENDS: A CASE STUDY FROM THE EAST TEXAS WOODLAND PERIOD
}

\author{
Robert Z Selden Jr \\ Ceramics Laboratory, Department of Anthropology, Texas A\&M University, College Station, Texas 77843, USA. \\ Email: zac_selden@tamu.edu.
}

\begin{abstract}
The East Texas Radiocarbon Database contributes to an analysis of tempo and place for Woodland era $(\sim 500 \mathrm{BC}-\mathrm{AD} 800)$ archaeological sites within the region. The temporal and spatial distributions of calibrated ${ }^{14} \mathrm{C}$ ages $(n=$ 127) with a standard deviation $(\Delta T)$ of 61 from archaeological sites with Woodland components $(n=51)$ are useful in exploring the development and geographical continuity of the peoples in east Texas, and lead to a refinement of our current chronological understanding of the period. While analysis of summed probability distributions (SPDs) produces less than significant findings due to sample size, they are used here to illustrate the method of date combination prior to the production of site- and periodspecific SPDs. Through the incorporation of this method, the number of ${ }^{14} \mathrm{C}$ dates is reduced to 85 with a $\Delta T$ of 54 . The resultant data set is then subjected to statistical analyses that conclude with the separation of the east Texas Woodland period into the Early Woodland ( $\sim 500 \mathrm{BC}-\mathrm{AD} 0)$, Middle Woodland ( AD 0-400), and Late Woodland ( AD 400-800) periods.
\end{abstract}

\section{INTRODUCTION}

Archaeologists have a lengthy history of tinkering with the manipulation of radiocarbon data, and have made much progress since first advocating for a more flexible method of processing data through the employment of a punch-card data retrieval system (see Taylor et al. 1968). Through the advent and acceptance of novel methodological approaches, we continue to make significant progress in our understanding and manipulation of regional cultural chronologies (Wendorf et al. 1979; Hassan 1984; Bever 2006; Bamforth and Grund 2012).

Rick's (1987) innovative explanation and subsequent employment of ${ }^{14} \mathrm{C}$ dates as data garnered acceptance and use within studies of occupational patterns and population dynamics (see Kuzmin and Keates 2005), which use the number of occupations - in lieu of the number of ${ }^{14} \mathrm{C}$ dates - as a method to view the spatial and temporal dynamics of human distribution (Straus et al. 2000). To that end, this study includes the assumptions that $(1){ }^{14} \mathrm{C}$ dates that can be combined via the $\mathrm{OxCal} X$ test represent a single occupational episode, (2) the summed probability distribution for archaeological sites with 4 or more ${ }^{14} \mathrm{C}$ assays illustrates the discrete or diffuse nature of occupational episodes, and (3) median dates represent the age of highest probability within each date range.

Through a variety of academic, avocational, and cultural resource management pursuits, archaeologists have obtained $127{ }^{14} \mathrm{C}$ dates from 51 Woodland period sites across east Texas (Tables 1 and 2). The bulk of these dates were collected with the intention of exploring locally based research questions and are employed here within a discussion of macrolevel trends, using a descriptive analysis of the results from date combination, summed probability distributions, and statistics to apprise the subsequent inferences (see Bernard 2006). While the distribution of recognized Woodland sites (or components) is easily plotted spatially, this paper represents the first attempt to synthesize these combined data and illustrate the temporal relationships that exist between ${ }^{14} \mathrm{C}$ dates collected across the east Texas region over the last $40 \mathrm{yr}$.

The East Texas Radiocarbon Database (ETRD) represents a sizeable sample of dates produced within a relatively small geographic region on the southwestern border of the Woodland culture area. This research refines our current knowledge regarding the temporal complexities within the Woodland period, providing a snapshot of temporal trends extracted from an understudied sample of ${ }^{14} \mathrm{C}$ dates. The temporal and spatial distributions of calibrated ${ }^{14} \mathrm{C}$ ages are useful in exploring the development and geographic continuity of the Woodland peoples and lead to a better understanding of the current chronological framework. From these data, it is possible to establish temporal associ- 
ations that correlate with site abandonment, decreases or increases in local populations, and an intensification of landscape usage throughout the Woodland period. These data are particularly helpful since paleoenvironmental models for east Texas are not able to be constructed due to the highly acidic soils (Bryant and Holloway 1985).

The inductive methodology employed here informs a regional chronology for east Texas Woodland sites (DeWalt and Pelto 1985). The goals of this article are to explore the process of ${ }^{14} \mathrm{C}$ date combination from sites with 4 or more samples $(n=11)$ to decrease sampling bias for statistical analysis and determine the modified summed probability distributions (see Michczyńska and Pazdur 2004; Bamforth and Grund 2012; Williams 2012), and secondly to employ the resulting median dates within a statistical analysis of regional trends.

\section{EAST TEXAS RADIOCARBON DATABASE}

Story (1990) provided the first published compendium of ${ }^{14} \mathrm{C}$ dates from east Texas, and the extensive ${ }^{14} \mathrm{C}$ database from investigations at Cooper Lake (Fields et al. 1997: Appendix B) led to Perttula's $(1997,1998)$ initial efforts to synthesize these data. In its current form, the ETRD is comprised of $1248{ }^{14} \mathrm{C}$ dates from a total of 199 archaeological sites that range in age from Paleoindian through Historic. This is a substantial increase from the 520 dates previously published (Perttula 1997; Perttula and Selden 2011), and the vast majority of the ${ }^{14} \mathrm{C}$ dates in the database are the product of cultural resource management (CRM) projects in east Texas.

\section{METHODS OF ANALYSIS}

${ }^{14} \mathrm{C}$ dates used within this research were collected from CRM reports and publications, were synthesized, then recalibrated with OxCal v 4.1.7 (Bronk Ramsey 2012) and IntCal09 (Reimer et al. 2009) (Table 1) (Perttula and Selden 2011). The completed database was analyzed using a variety of statistical processes (histograms, barplots, boxplots, kernel density, and hierarchical cluster analysis) within version 2.15.1 of R (http://www.r-project.org/), and summed probability distributions (SPDs) were produced using OxCal. Statistical calculations were made using negative numbers to represent $\mathrm{BC}$ and positive numbers to represent AD (Sirkin 2006).

With few exceptions where conventional ${ }^{14} \mathrm{C}$ ages were reported-to include older assays found to lack $\delta^{13} \mathrm{C}$ dates - value estimates were made for fractionation correction as suggested by Stuiver and Reimer (1993: Table 1): $-25 \%$ for nutshells and charcoal $\left(\mathrm{C}_{3}\right.$ plants), and $-10 \%$ for charred maize ( $\mathrm{C}_{4}$ plants).

The Woodland sample was selected from the ETRD on the basis of median age. If the median age fell within the currently accepted temporal construct ( $\sim 500$ BC-AD 800$)$ for the Woodland period (see Story 1990; Perttula and Nelson 2004; Perttula 2008a), it was included. Dates from sites found to lack geographic coordinates, with a standard deviation greater than $200 \mathrm{yr}$, or from non-archaeological contexts (i.e. geoarchaeological profile, backhoe trench, or cutbank not on a site) were removed from the sample. The remaining dates were combined and comprise the basis of the Woodland period statistical sample. Data fields from the ETRD include site name, trinomial (site number), assay number, raw age, $\delta^{13} \mathrm{C}$, corrected ${ }^{14} \mathrm{C}$ age, $2 \sigma$ age range, and median age (Table 2).

Within the distribution of Woodland ${ }^{14} \mathrm{C}$ assays $(n=127)$ from the ETRD, 28 sites were found to have $1{ }^{14} \mathrm{C}$ sample, 8 sites have 2 samples, 4 sites have 3 samples, 3 sites have 4 samples, 1 site has 5 samples, 3 sites have 6 samples, two have 7 samples, one has 9 samples, and one has 13 samples. The assays from the 11 sites with 4 or more ${ }^{14} \mathrm{C}$ dates were combined via $\mathrm{OxCal}$ for 2 reasons: (1) 
to reduce the standard deviation and increase the accuracy of each site's temporal assignments and (2) to reduce sampling bias created by the number of samples during statistical analyses.

Once combined, a summed probability distribution (SPD) was produced for each of the 11 sites to illustrate the position of each within the period. The dates were plotted in a manner where the SPDs, the combined groups, and the individual assays that inform them can be viewed together. These efforts permit the SPD for the entirety of the Woodland period sample to be contrast with those produced for the 11 sites. This comparison demonstrates the impact that each site has upon the whole of the Woodland period ${ }^{14} \mathrm{C}$ sample, and allows for a discussion of regional trends within the temporal sample.

This method expands the scholarly impact of existing ${ }^{14} \mathrm{C}$ dates through their integration within a regional chronology. By combining and recalibrating ${ }^{14} \mathrm{C}$ dates, and producing site-specific SPDs, the most accurate temporal representation available for the Woodland period in east Texas has been developed. The investigation contrasts site-specific summed probability distributions for 11 sites against the summed probability distribution for the entirety of the Woodland period sample.

Table 1 Data sources for the 51 archaeological sites examined in this study.

\begin{tabular}{ll}
\hline Trinomial $^{\text {a }}$ & Source \\
\hline 41AN38 & Lohse et al. 2004; Perttula et al. 2007, 2011 \\
41AN120 & Perttula 1997 \\
41BW692 & Lohse et al. 2004 \\
41CE19 & Story 1990; Davis et al. 1992; Perttula 2010a,b \\
41CP245 & Nelson and Perttula 2006 \\
41CP408 & Sherman 2004; Perttula and Ellis 2012 \\
41DT6 & Fields et al. 1993 \\
41DT16 & Fields et al. 1993 \\
41DT62 & Fields et al. 1993 \\
41DT141 & Fields et al. 1997 \\
41HO216 & Cooper and Cooper 2005; Perttula and Nelson 2006, 2007 \\
41HP78 & Doehner and Larson 1978 \\
41HP106 & Perttula 1999 \\
41HP137 & Fields et al. 1997 \\
41HS15 & Fields and Gadus 2012 \\
41HS16 & Webb et al. 1969 \\
41HS231 & Dockall et al. 2008 \\
41HS843 & Gadus et al. 2006 \\
41HS844 & Gadus et al. 2006 \\
41LR152 & Mahoney et al. 2001, 2002 \\
41LR164 & Mahoney et al. 2001, 2002 \\
41LR297 & Bruseth et al. 2009 \\
41MX5 & Brewington et al. 1995 \\
41NA49 & Corbin 1984; Corbin et al. 1984; Corbin and Hart 1998 \\
41NA231 & Perttula 2002, 2008b \\
41NA236 & Perttula 2000, 2002, 2008b \\
41NA243 & Perttula 2000, 2002 \\
41NA244 & Perttula 2000, 2002 \\
41NA248 & Perttula 2000, 2002 \\
41NA264 & Perttula 2000, 2002 \\
41NA280 & Perttula 2000, 2002 \\
41NA285 & Perttula 2000, 2002, 2008b \\
41NA290 & Perttula 2000, 2002 \\
& \\
&
\end{tabular}


Table 1 Data sources for the 51 archaeological sites examined in this study. (Continued)

\begin{tabular}{ll}
\hline Trinomial $^{\text {a }}$ & Source \\
\hline 41RK170 & Perttula and Nelson 2003 \\
41RK214 & Rogers and Perttula 2004; Perttula and Rogers 2007 \\
41RK222 & Rogers et al. 2001 \\
41RK328 & Cliff et al. 2004 \\
41RK468 & Dixon et al. 2009 \\
41RK558 & Dockall and Fields 2011 \\
41SM273 & Perttula and Nelson 2001, 2004 \\
41SY41 & Perttula 1997 \\
41TT370 & Kotter et al. 1993 \\
41TT372 & Barnhart et al. 1997 \\
41TT409 & Kotter et al. 1993 \\
41TT550 & Dixon et al. 1997; Perttula 1998 \\
41TT653 & Galan 1998; Perttula and Sherman 2009 \\
41TT847 & Hatfield et al. 2008 \\
41TT865 & Perttula et al. 2003; Hatfield et al. 2008 \\
41UR77 & Perttula and Ricklis 2005 \\
41UR133 & Parsons 1998 \\
41WD495 & Bruseth and Perttula 1981 \\
\hline
\end{tabular}

a"Trinomial" refers to the Smithsonian trinomial numbering system where the state is indicated by a number ranging from 1 to 50 , the county by $2-3$ capital letters, and the site within the county is represented by a number ranging from 1 to infinity.

Table $2{ }^{14} \mathrm{C}$ dates for the east Texas Woodland period. ${ }^{\mathrm{a}}$

\begin{tabular}{|c|c|c|c|c|c|c|c|}
\hline Trinomial $^{\mathrm{b}}$ & Sample nr & Raw age & $\begin{array}{l}\delta^{13} \mathrm{C} \\
(\%)\end{array}$ & $\begin{array}{l}\text { Corrected } \\
{ }^{14} \mathrm{C} \text { age }\end{array}$ & $1 \sigma$ age range & $2 \sigma$ age range & $\begin{array}{l}\text { Me- } \\
\text { dian }\end{array}$ \\
\hline 41AN038 & Beta-236778 & - & -26.2 & $1290 \pm 40$ & $\begin{array}{l}\text { AD } 670-722(0.43), \\
\text { AD } 741-770(0.25)\end{array}$ & $\begin{array}{l}\text { AD 653-783 }(0.91) \text {, } \\
\text { AD 789-812 (0.03), } \\
\text { AD 845-856 }(0.01)\end{array}$ & 722 \\
\hline 41AN038 & Beta-236790 & - & -25.8 & $1420 \pm 40$ & AD $604-655(0.68)$ & AD 565-666 (0.95) & 625 \\
\hline 41AN038 & Beta-236794 & 一 & -24.3 & $1830 \pm 50$ & AD 126-244 (0.68) & $\begin{array}{l}\text { AD 70-263 }(0.87) \\
\text { AD 278-329 }(0.08)\end{array}$ & 184 \\
\hline 41AN120 & SMU-669 & $1744 \pm 64$ & & $1744 \pm 76$ & AD 215-401 (0.68) & $\begin{array}{l}\text { AD 83-434 (0.95), } \\
\text { AD 495-505 (0.01) }\end{array}$ & 290 \\
\hline 41BW692 & UGA-13420 & $1270 \pm 40$ & -24.7 & $1280 \pm 40$ & $\begin{array}{l}\text { AD 676-729 (0.40), } \\
\text { AD 736-772 (0.28) }\end{array}$ & $\begin{array}{l}\text { AD 657-825 (0.93), } \\
\text { AD 841-862 (0.03) }\end{array}$ & 730 \\
\hline 41CE019 & Tx-1223 & $1290 \pm 80$ & 一 & $1266 \pm 90$ & $\begin{array}{l}\text { AD } 665-826(0.61) \\
\text { AD } 840-863(0.07)\end{array}$ & AD 622-972 (0.95) & 767 \\
\hline 41CE019 & Tx-919 & $1310 \pm 80$ & 一 & $1286 \pm 90$ & $\begin{array}{l}\text { AD } 665-820(0.63) \\
\text { AD } 842-860(0.05)\end{array}$ & $\begin{array}{l}\text { AD 602-901 (0.91), } \\
\text { AD 917-966 (0.04) }\end{array}$ & 751 \\
\hline 41CE019 & Tx-105 & $1120 \pm 90$ & 一 & $1361 \pm 99$ & AD 582-775 (0.68) & $\begin{array}{l}\text { AD } 436-490(0.03) \text {, } \\
\text { AD 510-517 }(0.00), \\
\text { AD 530-891 }(0.92)\end{array}$ & 676 \\
\hline 41CE019 & Tx-674 & $1420 \pm 100$ & 一 & $1396 \pm 108$ & $\begin{array}{l}\text { AD 542-723 (0.61), } \\
\text { AD 740-770 (0.07) }\end{array}$ & AD 425-877 (0.95) & 639 \\
\hline 41CE019 & Tx-3312 & $1190 \pm 80$ & 一 & $1431 \pm 90$ & $\begin{array}{l}\text { AD } 471-477(0.01) \text {, } \\
\text { AD 535-683(0.67) }\end{array}$ & AD 422-773 (0.95) & 606 \\
\hline 41CE019 & - & $1630 \pm 40$ & -26.7 & $1600 \pm 40$ & $\begin{array}{l}\text { AD 418-466 (0.31), } \\
\text { AD 482-533(0.37) }\end{array}$ & AD 382-560 (0.95) & 473 \\
\hline 41CE019 & Tx-3695 & $1400 \pm 60$ & - & $1641 \pm 72$ & $\begin{array}{l}\text { AD } 337-468(0.49) \text {, } \\
\text { AD } 479-534(0.18)\end{array}$ & AD $240-570(0.95)$ & 411 \\
\hline $41 \mathrm{CP} 245$ & Beta-208773 & $1320 \pm 40$ & -27.5 & $1280 \pm 40$ & $\begin{array}{l}\text { AD } 676-729(0.40) \text {, } \\
\text { AD } 736-772(0.28)\end{array}$ & $\begin{array}{l}\text { AD } 657-825(0.93), \\
\text { AD } 841-862(0.03)\end{array}$ & 730 \\
\hline $41 \mathrm{CP} 245$ & Beta-208775 & $1730 \pm 40$ & -27.3 & $1690 \pm 40$ & $\begin{array}{l}\text { AD } 261-280(0.11) \text {, } \\
\text { AD } 326-410(0.58)\end{array}$ & AD $249-426(0.95)$ & 353 \\
\hline
\end{tabular}


Table $2{ }^{14} \mathrm{C}$ dates for the east Texas Woodland period. ${ }^{\mathrm{a}}$ (Continued)

\begin{tabular}{|c|c|c|c|c|c|c|c|}
\hline Trinomial $^{\mathrm{b}}$ & Sample nr & Raw age & $\begin{array}{l}\delta^{13} \mathrm{C} \\
(\%)\end{array}$ & $\begin{array}{l}\text { Corrected } \\
{ }^{14} \mathrm{C} \text { age }\end{array}$ & $1 \sigma$ age range & $2 \sigma$ age range & $\begin{array}{l}\text { Me- } \\
\text { dian }\end{array}$ \\
\hline $41 \mathrm{CP} 408$ & Beta-184988 & $1930 \pm 40$ & -25.9 & $1920 \pm 40$ & $\begin{array}{l}\text { AD } 29-38(0.05), \\
\text { AD } 51-128(0.63)\end{array}$ & $\begin{array}{l}20-13 \text { BC }(0.01) \\
1 \text { BC-AD } 215(0.95)\end{array}$ & 83 \\
\hline 41DT006 & Beta-51364 & $1270 \pm 60$ & -26.2 & $1250 \pm 60$ & $\begin{array}{l}\text { AD } 680-818(0.62) \text {, } \\
\text { AD } 843-860(0.06)\end{array}$ & $\begin{array}{l}\text { AD } 657-895(0.95) \\
\text { AD } 927-935(0.01)\end{array}$ & 768 \\
\hline 41DT006 & Beta-51366 & $1300 \pm 80$ & -25.0 & $1300 \pm 80$ & $\begin{array}{l}\text { AD 649-782 (0.63), } \\
\text { AD 790-809 (0.05) }\end{array}$ & $\begin{array}{l}\text { AD 599-895 (0.95), } \\
\text { AD 925-937 (0.01) }\end{array}$ & 736 \\
\hline 41DT006 & Beta-51367 & $1370 \pm 80$ & -25.5 & $1370 \pm 80$ & $\begin{array}{l}\text { AD } 595-718(0.59) \text {, } \\
\text { AD } 743-769(0.10)\end{array}$ & AD 536-876 (0.95) & 663 \\
\hline 41DT006 & Beta-51368 & $1470 \pm 80$ & -25.8 & $1460 \pm 80$ & $\begin{array}{l}\text { AD } 470-478(0.02) \text {, } \\
\text { AD 535-660 (0.66) }\end{array}$ & $\begin{array}{l}\text { AD 414-689 }(0.95) \text {, } \\
\text { AD 753-760 }(0.00)\end{array}$ & 583 \\
\hline 41DT006 & Beta-51365 & $1790 \pm 100$ & -26.1 & $1770 \pm 100$ & $\begin{array}{l}\text { AD 134-354 (0.65), } \\
\text { AD 366-381 (0.04) }\end{array}$ & $\begin{array}{l}\text { AD 27-41 (0.01), } \\
\text { AD 48-442 (0.92), } \\
\text { AD 455-460 (0.00), } \\
\text { AD 484-532(0.03) }\end{array}$ & 258 \\
\hline 41DT016 & Beta-52241 & $1300 \pm 60$ & -25.5 & $1290 \pm 60$ & AD $663-775(0.68)$ & AD 649-878 (0.95) & 735 \\
\hline 41DT016 & Beta-51372 & $1300 \pm 80$ & -26.0 & $1290 \pm 80$ & $\begin{array}{l}\text { AD 654-782 (0.60), } \\
\text { AD 789-810 (0.06), } \\
\text { AD 848-855 (0.02) }\end{array}$ & $\begin{array}{l}\text { AD 606-897 (0.94), } \\
\text { AD 923-941 (0.01) }\end{array}$ & 744 \\
\hline 41DT016 & Beta-52242 & $1330 \pm 70$ & -25.9 & $1310 \pm 70$ & AD 652-776 (0.68) & AD 612-883 (0.95) & 723 \\
\hline 41DT016 & Beta-52245 & $1520 \pm 60$ & -24.8 & $1530 \pm 60$ & $\begin{array}{l}\text { AD } 436-491(0.28), \\
\text { AD 509-518 (0.04), } \\
\text { AD 529-596 (0.37) }\end{array}$ & AD 416-641 (0.95) & 525 \\
\hline 41DT016 & Beta-52244 & $1550 \pm 90$ & -24.8 & $1560 \pm 90$ & AD 415-592 (0.68) & $\begin{array}{l}\text { AD 260-283 }(0.02), \\
\text { AD 324-652 }(0.94)\end{array}$ & 490 \\
\hline 41DT016 & Beta-51371 & $2090 \pm 90$ & -25.7 & $2080 \pm 90$ & $\begin{array}{l}336-331 \text { BC }(0.00), \\
203 \text { BC-AD } 21(0.67)\end{array}$ & $365 \mathrm{BC}-77 \mathrm{AD}(0.95)$ & -112 \\
\hline 41DT062 & Beta-52605 & $1370 \pm 110$ & -24.8 & $1380 \pm 110$ & AD 556-773 (0.68) & AD 430-886 (0.95) & 657 \\
\hline 41DT141 & Beta- 17400 & $2100 \pm 70$ & 一 & $2100 \pm 81$ & $\begin{array}{l}347-321 \text { BC }(0.06), \\
206-37 \text { BC }(0.58), \\
30-21 \text { BC }(0.02), \\
11-2 \text { BC }(0.02)\end{array}$ & 363 BC-AD 53 (0.95) & -134 \\
\hline 41DT141 & Beta-17401 & $2350 \pm 70$ & - & $2350 \pm 81$ & $\begin{array}{l}733-691 \text { ВC }(0.08), \\
662-650 \text { BC }(0.02), \\
545-359 \text { ВC }(0.55), \\
276-259 \text { ВC }(0.03)\end{array}$ & $\begin{array}{l}761-682 \mathrm{BC}(0.12), \\
\mathrm{AD} 671-347 \mathrm{BC} \\
(0.69), \\
320-206 \mathrm{BC}(0.14)\end{array}$ & -465 \\
\hline $41 \mathrm{HO} 216$ & Beta-206843 & $1540 \pm 70$ & -26.5 & $1520 \pm 70$ & $\begin{array}{l}\text { AD } 435-491(0.25) \text {, } \\
\text { AD 509-518 }(0.04) \text {, } \\
\text { AD 529-606 (0.40) }\end{array}$ & AD 409-651 (0.95) & 534 \\
\hline 41НP078 & SMU-1978 & 一 & -26.4 & $1810 \pm 110$ & AD $81-339(0.68)$ & $\begin{array}{l}46 \text { BC-AD } 436(0.94) \text {, } \\
\text { AD } 490-510(0.01), \\
\text { AD 517-529 }(0.00)\end{array}$ & 212 \\
\hline 41HP078 & Tx-1961 & $2080 \pm 60$ & 一 & $2080 \pm 72$ & $\begin{array}{l}196-20 \mathrm{BC}(0.65), \\
12-1 \mathrm{BC}(0.03)\end{array}$ & $\begin{array}{l}357-285 \text { BC }(0.09), \\
255-249 \text { BC }(0.04), \\
234 \text { BC-AD } 67(0.86)\end{array}$ & -108 \\
\hline 41HP106 & Beta- 82913 & $1730 \pm 100$ & -27.6 & $1710 \pm 100$ & $\begin{array}{l}\text { AD 175-192 (0.03), } \\
\text { AD 212-433 (0.65) }\end{array}$ & AD 85-547 (0.95) & 325 \\
\hline 41HP106 & Beta-82914 & $1820 \pm 90$ & -25.4 & $1810 \pm 90$ & $\begin{array}{l}\text { AD 86-106 (0.5), } \\
\text { AD 120-264 (0.48), } \\
\text { AD 276-332 (0.15) }\end{array}$ & AD $18-417(0.95)$ & 212 \\
\hline 41HP106 & Beta-82915 & $1820 \pm 50$ & -24.1 & $1840 \pm 50$ & $\begin{array}{l}\text { AD 93-97 (0.02), } \\
\text { AD 125-238 (0.66) }\end{array}$ & $\begin{array}{l}\text { AD } 62-260(0.90), \\
\text { AD 282-324 }(0.05)\end{array}$ & 175 \\
\hline 41HP106 & Beta- 85866 & $1860 \pm 50$ & -24.6 & $1860 \pm 50$ & $\begin{array}{l}\text { AD } 86-109(0.12) \\
\text { AD } 117-220(0.56)\end{array}$ & $\begin{array}{l}\text { AD 29-39 }(0.01) \\
\text { AD 51-256(0.93), } \\
\text { AD 303-316(0.01) }\end{array}$ & 156 \\
\hline 41HP106 & Beta-82917 & $1880 \pm 90$ & -25.9 & $1870 \pm 90$ & $\begin{array}{l}\text { AD } 29-39(0.02), \\
\text { AD } 50-245(0.66)\end{array}$ & $49 \mathrm{BC}-\mathrm{AD} 382(0.95)$ & 146 \\
\hline 41HP106 & Beta- 85868 & $1910 \pm 50$ & -26.2 & $1890 \pm 50$ & $\begin{array}{l}\text { AD } 61-172(0.61) \\
\text { AD } 193-211(0.07)\end{array}$ & AD 5-240 (0.95) & 118 \\
\hline 41HP106 & Beta- 85867 & $2270 \pm 50$ & -26.7 & $2250 \pm 50$ & $\begin{array}{l}389-352 \text { BC }(0.23), \\
296-228 \text { BC }(0.40), \\
221-211 \text { BC }(0.05)\end{array}$ & $398-202$ BC (0.95) & -287 \\
\hline
\end{tabular}


Table $2{ }^{14} \mathrm{C}$ dates for the east Texas Woodland period. ${ }^{\mathrm{a}}$ (Continued)

\begin{tabular}{|c|c|c|c|c|c|c|c|}
\hline Trinomial $^{\mathrm{b}}$ & Sample nr & Raw age & $\begin{array}{l}\delta^{13} \mathrm{C} \\
(\%)\end{array}$ & $\begin{array}{l}\text { Corrected } \\
{ }^{14} \mathrm{C} \text { age }\end{array}$ & $1 \sigma$ age range & $2 \sigma$ age range & $\begin{array}{l}\text { Me- } \\
\text { dian }\end{array}$ \\
\hline 41HP137 & SMU-1966 & - & -25.2 & $1460 \pm 60$ & AD 555-647 (0.68) & $\begin{array}{l}\text { AD } 434-493(0.10), \\
\text { AD 507-520 }(0.02), \\
\text { AD 527-666 (0.84) }\end{array}$ & 592 \\
\hline 41HP137 & SMU-1917 & - & -25.7 & $2090 \pm 30$ & $\begin{array}{l}164-129 \text { BC }(0.26), \\
121-88 \mathrm{BC}(0.25), \\
78-55 \text { BC }(0.17)\end{array}$ & $196-42 \mathrm{BC}(0.95)$ & -112 \\
\hline 41HS015 & Beta-242049 & $1450 \pm 40$ & -23.7 & $1470 \pm 40$ & AD 565-635 (0.68) & $\begin{array}{l}\text { AD 467-481, } \\
\text { AD 534-665(0.99) }\end{array}$ & 594 \\
\hline 41HS016 & Tx-483 & $1850 \pm 90$ & - & $1850 \pm 99$ & $\begin{array}{l}\text { AD 54-259 (0.63), } \\
\text { AD 296-321 (0.05) }\end{array}$ & $\mathrm{AD} 47-406(0.95)$ & 169 \\
\hline 41HS016 & $\mathrm{Tx}-481$ & $2150 \pm 100$ & - & $2150 \pm 108$ & $\begin{array}{l}359-278 \text { ВC }(0.21), \\
259-241 \text { BC }(0.04), \\
236-88 \text { BC }(0.39), \\
78-55 \text { ВC }(0.05)\end{array}$ & $402 \mathrm{BC}-61 \mathrm{AD}(0.95)$ & -194 \\
\hline 41HS016 & Tx-484 & $2360 \pm 130$ & - & $2360 \pm 136$ & $\begin{array}{l}752-686 \text { BC }(0.11), \\
667-636 \text { BC }(0.05), \\
623-614 \text { BC }(0.01), \\
595-357 \text { BC }(0.45), \\
283-257 \text { BC }(0.04), \\
246-235 \text { BC }(0.02)\end{array}$ & $\begin{array}{l}802-159 \text { BC }(0.95), \\
134-116 \text { BC }(0.01)\end{array}$ & -480 \\
\hline 41HS231 & Beta-236382 & $1300 \pm 40$ & -26.2 & $1280 \pm 40$ & $\begin{array}{l}\text { AD 676-729 }(0.40), \\
\text { AD 736-772 }(0.28)\end{array}$ & $\begin{array}{l}\text { AD } 657-825(0.93), \\
\text { AD } 841-862(0.03)\end{array}$ & 730 \\
\hline $41 \mathrm{HS} 231$ & Beta-236383 & $1290 \pm 40$ & -25.4 & $1280 \pm 40$ & $\begin{array}{l}\text { AD 676-729 }(0.40) \text {, } \\
\text { AD } 736-772(0.28)\end{array}$ & $\begin{array}{l}\text { AD } 657-825(0.93), \\
\text { AD } 841-862(0.03)\end{array}$ & 730 \\
\hline 41HS231 & Beta-236388 & $1470 \pm 40$ & -25.2 & $1470 \pm 40$ & AD 565-635 (0.68) & $\begin{array}{l}\text { AD } 467-481(0.01) \\
\text { AD } 534-655(0.94)\end{array}$ & 594 \\
\hline $41 \mathrm{HS} 843$ & Beta-210245 & $1930 \pm 40$ & -25.3 & $1930 \pm 40$ & $\begin{array}{l}\text { AD 27-42 (0.10), } \\
\text { AD 48-125 (0.58) }\end{array}$ & $\begin{array}{l}\text { BC 40-AD } 170(0.92) \text {, } \\
\text { AD 150-170 (0.02), } \\
\text { AD 195-210 (0.01) }\end{array}$ & 72 \\
\hline $41 \mathrm{HS} 844$ & Beta-210247 & $1820 \pm 40$ & -25.6 & $1810 \pm 40$ & AD 136-243 (0.68) & $\begin{array}{l}\text { AD } 86-109(0.03) \\
\text { AD 120-264 }(0.80) \\
\text { AD 275-334 }(0.13)\end{array}$ & 201 \\
\hline 41LR152 & Beta- 153588 & - & -28.7 & $1240 \pm 60$ & $\begin{array}{l}\text { AD 688-827 (0.59), } \\
\text { AD 840-864 (0.09) }\end{array}$ & $\begin{array}{l}\text { AD 660-897 (0.94), } \\
\text { AD 923-940 (0.02) }\end{array}$ & 779 \\
\hline 41LR164 & Beta-153591 & - & -21.0 & $2040 \pm 40$ & 106 BC-AD $17(0.68)$ & $\begin{array}{l}\text { BC 168-AD } 30(0.92) \text {, } \\
\text { AD 37-52 }(0.03)\end{array}$ & -50 \\
\hline 41LR164 & Beta-153593 & - & -21.2 & $2180 \pm 40$ & $\begin{array}{l}356-286 \text { BC }(0.40), \\
234-177 \text { BC }(0.28)\end{array}$ & $\begin{array}{l}379-154 \text { BC }(0.92) \\
137-114 \text { BC }(0.03)\end{array}$ & -268 \\
\hline 41LR164 & Beta- 153592 & - & -20.6 & $2320 \pm 40$ & $\begin{array}{l}412-360 \text { BC }(0.63), \\
274-260 \text { BC }(0.05)\end{array}$ & $\begin{array}{l}514-352 \text { BC }(0.79), \\
295-229 \text { BC }(0.16), \\
220-212 \text { BC }(0.01)\end{array}$ & -391 \\
\hline 41LR297 & Beta-239524 & $1290 \pm 40$ & -25.9 & & 8067177460 & AD 656-870 (0.95) & 736 \\
\hline & Beta- 237680 & $1480 \pm 40$ & & & AD 550-621 (0.68) & $\begin{array}{l}\text { AD 441-484 (0.06), } \\
\text { AD 532-652 (0.90) }\end{array}$ & 586 \\
\hline 41LR297 & Beta & $570+5=$ & -24.9 & & & AD 394-600 (0.95) & 489 \\
\hline 41LR297 & Beta-237678 & $2340 \pm 50$ & -25.1 & & $511-371$ ВC (0.68) & $\begin{array}{l}736-689 \text { BC }(0.05), \\
663-648 \text { BC }(0.01), \\
548-352 \text { BC }(0.80), \\
296-228 \text { BC }(0.07), \\
221-211 \text { BC }(0.01)\end{array}$ & -417 \\
\hline 41MX005 & Beta-52709 & $1790 \pm 90$ & - & $1790 \pm 99$ & $\begin{array}{l}\text { AD 126-350 (0.66), } \\
\text { AD 368-379 (0.02) }\end{array}$ & $\begin{array}{l}\text { AD 2-435 (0.94), } \\
\text { AD 491-509 (0.01), } \\
\text { AD 518-529 }(0.00)\end{array}$ & 235 \\
\hline 41NA049 & Tx-4876 & $1280 \pm 100$ & - & & & AD 576-984 (0.95) & 760 \\
\hline 41NA231 & Beta-136806 & $1700 \pm 40$ & -26.3 & $1680 \pm 40$ & $\begin{array}{l}\text { AD 264-276 }(0.06) \text {, } \\
\text { AD 333-415 (0.62) }\end{array}$ & $\begin{array}{l}\text { AD 245-434 (0.95), } \\
\text { AD 495-505 (0.01) }\end{array}$ & 363 \\
\hline 41NA231 & Beta-204778 & $1970 \pm 70$ & -25.9 & $1960 \pm 70$ & $\begin{array}{l}42 \text { BC-AD } 90(0.60), \\
\text { AD } 100-124(0.08)\end{array}$ & $\begin{array}{l}159-135 \text { BC }(0.02), \\
116 \text { BC-AD } 221 \\
(0.93)\end{array}$ & 37 \\
\hline 41NA236 & Beta- 183857 & $1280 \pm 60$ & -19.0 & $1380 \pm 60$ & AD 598-688 (0.68) & AD 558-773 (0.95) & 651 \\
\hline
\end{tabular}


Table $2{ }^{14} \mathrm{C}$ dates for the east Texas Woodland period. ${ }^{\mathrm{a}}$ (Continued)

\begin{tabular}{|c|c|c|c|c|c|c|c|}
\hline Trinomial $^{\mathrm{b}}$ & Sample nr & Raw age & $\begin{array}{l}\delta^{13} \mathrm{C} \\
(\%)\end{array}$ & $\begin{array}{l}\text { Corrected } \\
{ }^{14} \mathrm{C} \text { age }\end{array}$ & $1 \sigma$ age range & $2 \sigma$ age range & $\begin{array}{l}\text { Me- } \\
\text { dian }\end{array}$ \\
\hline 41NA236 & Beta-203667 & $1410 \pm 90$ & -24.6 & $1420 \pm 90$ & $\begin{array}{l}\text { AD 537-689 (0.67), } \\
\text { AD 753-760 (0.01) }\end{array}$ & AD 420-778 (0.95) & 615 \\
\hline 41NA236 & Beta-204783 & $1470 \pm 40$ & -24.7 & $1470 \pm 40$ & AD 565-635 (0.68) & $\begin{array}{l}\text { AD } 467-481(0.01) \text {, } \\
\text { AD 534-655 (0.94) }\end{array}$ & 594 \\
\hline 41NA236 & Beta-203666 & $1560 \pm 40$ & -24.8 & $1560 \pm 40$ & $\begin{array}{l}\text { AD } 434-495(0.42), \\
\text { AD 504-543(0.26) }\end{array}$ & AD $415-585(0.95)$ & 492 \\
\hline 41NA236 & Beta-204782 & $1830 \pm 40$ & -24.8 & $1830 \pm 40$ & AD 134-230 (0.68) & $\begin{array}{l}\text { AD } 80-258(0.93), \\
\text { AD 300-318 (0.03) }\end{array}$ & 182 \\
\hline 41NA236 & Beta-203669 & $1850 \pm 90$ & -24.9 & $1850 \pm 90$ & AD $61-256(0.66)$ & $39 \mathrm{BC}-\mathrm{AD} 385(0.95)$ & 169 \\
\hline 41NA236 & Beta-151097 & $1920 \pm 40$ & -25.4 & $1910 \pm 40$ & $\begin{array}{l}\text { AD 31-37 (0.03), } \\
\text { AD 52-132 (0.66) }\end{array}$ & AD 5-216 (0.95) & 95 \\
\hline 41NA236 & Beta-203668 & $2000 \pm 60$ & -24.6 & $2010 \pm 60$ & $\begin{array}{l}91-70 \mathrm{BC}(0.07), \\
60 \mathrm{BC}-\mathrm{AD} 65(0.61)\end{array}$ & $\begin{array}{l}174 \text { BC-AD } 90(0.93) \text {, } \\
\text { AD } 100-124(0.03)\end{array}$ & -19 \\
\hline 41NA236 & Beta-151098 & $2370 \pm 40$ & -24.7 & $2370 \pm 40$ & $\begin{array}{l}510-436 \text { BC }(0.43), \\
426-393 \text { BC }(0.26)\end{array}$ & $\begin{array}{l}735-690 \text { BC }(0.07), \\
663-649 \text { BC }(0.01), \\
546-382 \text { ВС }(0.87)\end{array}$ & -463 \\
\hline 41NA243 & Beta-154853 & $1770 \pm 70$ & -26.2 & $1750 \pm 70$ & AD 215-391 (0.68) & $\begin{array}{l}\text { AD 86-106 (0.01), } \\
\text { AD 121-428 (0.94) }\end{array}$ & 285 \\
\hline 41NA243 & Beta-154854 & $2350 \pm 60$ & -25.3 & $2350 \pm 60$ & $\begin{array}{l}702-696 \text { BC }(0.01), \\
538-369 \text { ВС }(0.67)\end{array}$ & $\begin{array}{l}752-686 \text { BC }(0.10), \\
668-637 \text { BC }(0.03), \\
622-614 \text { BC }(0.00), \\
595-352 \text { BC }(0.74), \\
296-228 \text { BC }(0.07), \\
221-211 \text { BC }(0.01)\end{array}$ & -454 \\
\hline 41NA244 & Beta-151102 & $1820 \pm 40$ & -23.6 & $1840 \pm 40$ & AD 130-226 (0.68) & $\begin{array}{l}\text { AD } 75-255(0.95), \\
\text { AD } 305-313(0.01)\end{array}$ & 174 \\
\hline 41NA248 & Beta-151104 & $1670 \pm 40$ & -26.0 & $1650 \pm 40$ & $\begin{array}{l}\text { AD 338-434 (0.65), } \\
\text { AD 495-504 (0.03) }\end{array}$ & $\begin{array}{l}\text { AD 260-284 (0.05), } \\
\text { AD 323-520 (0.90) }\end{array}$ & 400 \\
\hline 41NA264 & Beta-151105 & $2370 \pm 110$ & -26.7 & $2340 \pm 100$ & $\begin{array}{l}733-691 \text { BC }(0.08), \\
662-650 \text { BC }(0.02), \\
545-353 \text { BC }(0.47), \\
293-230 \text { BC }(0.11), \\
219-213(0.01)\end{array}$ & 767-198 BC (0.95) & -451 \\
\hline 41NA280 & Beta-151107 & $1950 \pm 40$ & -24.8 & $1950 \pm 40$ & $\begin{array}{l}\text { AD 3-85 (0.66), } \\
\text { AD 110-115(0.02) }\end{array}$ & 41 BC-AD $129(0.95)$ & 50 \\
\hline 41NA285 & Beta-221421 & $1250 \pm 40$ & -25.5 & $1240 \pm 40$ & $\begin{array}{l}\text { AD } 690-752(0.36), \\
\text { AD } 761-783(0.12) \\
\text { AD } 788-815(0.13), \\
\text { AD } 844-859(0.06)\end{array}$ & AD 680-882 (0.95) & 772 \\
\hline 41NA285 & Beta-201990 & $1240 \pm 40$ & -23.9 & $1260 \pm 40$ & AD 680-779 (0.68) & AD 668-870 (0.95) & 744 \\
\hline 41NA285 & Beta-204786 & $1340 \pm 40$ & -25.6 & $1330 \pm 40$ & $\begin{array}{l}\text { AD } 652-695(0.50) \text {, } \\
\text { AD } 701-707(0.04) \text {, } \\
\text { AD } 748-765(0.14)\end{array}$ & AD 643-774 (0.95) & 686 \\
\hline 41NA285 & Beta-221420 & $1560 \pm 40$ & -23.2 & $1590 \pm 40$ & $\begin{array}{l}\text { AD } 425-468(0.30) \text {, } \\
\text { AD } 480-534(0.40)\end{array}$ & AD 392-562 (0.95) & 480 \\
\hline 41NA285 & Beta-151112 & $2100 \pm 40$ & -25.7 & $2090 \pm 40$ & $166-54 \mathrm{BC}(0.68)$ & $\begin{array}{l}338-330 \mathrm{BC}(0.01), \\
204 \mathrm{BC}-\mathrm{AD} 2(0.95)\end{array}$ & -113 \\
\hline 41NA285 & Beta-201989 & $2170 \pm 40$ & -26.1 & $2150 \pm 40$ & $\begin{array}{l}351-299 \text { BC }(0.24), \\
228-223 \text { BC }(0.02), \\
210-151 \text { BC }(0.32), \\
140-112 \text { BC }(0.11)\end{array}$ & $\begin{array}{l}359-277 \mathrm{BC}(0.30), \\
260-87 \mathrm{BC}(0.62), \\
78-55 \mathrm{BC}(0.04)\end{array}$ & -196 \\
\hline 41NA290 & Beta-151116 & $1380 \pm 40$ & -24.5 & $1390 \pm 40$ & AD 617-665 (0.68) & AD 573-688 (0.95) & 644 \\
\hline 41RK170 & Beta-166761 & $2110 \pm 40$ & -24.0 & $2130 \pm 40$ & $\begin{array}{l}342-326 \text { BC }(0.06), \\
204-94 \text { BC }(0.62)\end{array}$ & $\begin{array}{l}355-290 \text { BC }(0.16), \\
232-46 \text { BC }(0.79)\end{array}$ & -163 \\
\hline 41RK214 & B-107402** & $1130 \pm 50$ & -18.4 & $1240 \pm 50$ & $\begin{array}{l}\text { AD } 689-753(0.33), \\
\text { AD 760-822 }(0.27) \text {, } \\
\text { AD } 842-861(0.08)\end{array}$ & AD 669-890 (0.95) & 775 \\
\hline 41RK214 & Beta- 81680 & $1810 \pm 60$ & -23.4 & $1830 \pm 60$ & $\begin{array}{l}\text { AD 88-103(0.05), } \\
\text { AD } 122-251(0.63)\end{array}$ & AD 55-343 (0.95) & 186 \\
\hline
\end{tabular}


Table $2{ }^{14} \mathrm{C}$ dates for the east Texas Woodland period. ${ }^{\mathrm{a}}$ (Continued)

\begin{tabular}{|c|c|c|c|c|c|c|c|}
\hline Trinomial $^{\mathrm{b}}$ & Sample nr & Raw age & $\begin{array}{l}\delta^{13} \mathrm{C} \\
(\%)\end{array}$ & $\begin{array}{l}\text { Corrected } \\
{ }^{14} \mathrm{C} \text { age }\end{array}$ & $1 \sigma$ age range & $2 \sigma$ age range & $\begin{array}{l}\text { Me- } \\
\text { dian }\end{array}$ \\
\hline 41RK222 & Beta- 60093 & $1400 \pm 70$ & -24.3 & $1410 \pm 70$ & AD 568-671 (0.68) & $\begin{array}{l}\text { AD 439-486 (0.04), } \\
\text { AD 532-730 (0.87), } \\
\text { AD 735-772 (0.05) }\end{array}$ & 626 \\
\hline 41RK222 & Beta-60094 & $1840 \pm 100$ & -24.8 & $1840 \pm 100$ & $\begin{array}{l}\text { AD 64-260 }(0.60), \\
\text { AD 284-323 }(0.09)\end{array}$ & 44 BC-AD $410(0.95)$ & 180 \\
\hline 41RK222 & Beta-72776 & $1880 \pm 80$ & -26.5 & $1850 \pm 80$ & AD $70-250(0.68)$ & $\begin{array}{l}20-13 \mathrm{BC}(0.00) \\
\mathrm{AD} 1-382(0.95)\end{array}$ & 168 \\
\hline 41RK222 & Beta-72770 & $1840 \pm 60$ & -23.2 & $1870 \pm 60$ & AD 78-217 (0.68) & $\begin{array}{l}\text { AD 3-259 (0.93), } \\
\text { AD 295-322(0.02) }\end{array}$ & 145 \\
\hline 41RK222 & Beta-72778 & $1860 \pm 45$ & -22.0 & $1905 \pm 50$ & $\begin{array}{l}\text { AD 26-139 (0.62), } \\
\text { AD 158-166 (0.02), } \\
\text { AD 196-209 (0.04) }\end{array}$ & $\begin{array}{l}19-14 \text { BC }(0.01), \\
\text { AD } 1-235(0.95)\end{array}$ & 102 \\
\hline 41RK222 & Beta-72771 & $1980 \pm 100$ & -24.6 & $1990 \pm 100$ & $\begin{array}{l}151-140 \text { BC }(0.02), \\
112 \text { BC-AD } 126(0.66)\end{array}$ & $\begin{array}{l}351-298 \text { BC }(0.03), \\
228-222 \text { BC }(0.00), \\
211 \text { BC-AD } 242 \\
(0.92)\end{array}$ & -4 \\
\hline 41RK328 & - & - & - & $1610 \pm 40$ & $\begin{array}{l}\text { AD } 408-465(0.35), \\
\text { AD 482-533(0.33) }\end{array}$ & $\begin{array}{l}\text { AD 348-369 (0.03), } \\
\text { AD 379-547 (0.93) }\end{array}$ & 463 \\
\hline 41RK468 & Beta-239710 & $2150 \pm 40$ & -26.5 & $2130 \pm 40$ & $\begin{array}{l}342-326 \mathrm{BC}(0.06), \\
204-94 \mathrm{BC}(0.62)\end{array}$ & $\begin{array}{l}355-290 \text { BC }(0.16), \\
232-46 \text { ВC }(0.79)\end{array}$ & -163 \\
\hline 41RK558 & Beta-278035 & $1280 \pm 40$ & -25.9 & $1270 \pm 40$ & AD 682-774 (0.68) & $\begin{array}{l}\text { AD } 662-830(0.89), \\
\text { AD } 836-869(0.06)\end{array}$ & 737 \\
\hline $41 \mathrm{SM} 273$ & Beta-157990 & $1270 \pm 40$ & -25.7 & $1260 \pm 40$ & AD 680-779 (0.68) & AD $668-870(0.95)$ & 744 \\
\hline 41SM273 & Beta-173089 & $1310 \pm 40$ & -26.0 & $1290 \pm 40$ & $\begin{array}{l}\text { AD } 670-722(0.43) \text {, } \\
\text { AD 741-770 (0.25) }\end{array}$ & $\begin{array}{l}\text { AD } 653-783(0.91), \\
\text { AD 789-812 (0.03), } \\
\text { AD 845-856 (0.01) }\end{array}$ & 722 \\
\hline 41SM273 & Beta- 154860 & $1400 \pm 60$ & -25.0 & $1400 \pm 60$ & AD 588-673 (0.68) & $\begin{array}{l}\text { AD 540-721 (0.91), } \\
\text { AD 741-770 (0.04) }\end{array}$ & 634 \\
\hline 41SM273 & Beta-157989 & $1490 \pm 70$ & -25.7 & $1480 \pm 70$ & $\begin{array}{l}\text { AD } 469-479(0.03) \text {, } \\
\text { AD } 534-650(0.65)\end{array}$ & AD 427-661 (0.95) & 571 \\
\hline 41SM273 & Beta-173091 & $1520 \pm 40$ & -24.9 & $1520 \pm 40$ & $\begin{array}{l}\text { AD } 442-484(0.19) \text {, } \\
\text { AD 532-601 (0.49) }\end{array}$ & AD 430-617 (0.95) & 546 \\
\hline 41SM273 & Beta-154857 & $1550 \pm 80$ & -26.0 & $1530 \pm 80$ & $\begin{array}{l}\text { AD } 433-497(0.27) \text {, } \\
\text { AD 503-599 }(0.42)\end{array}$ & $\begin{array}{l}\text { AD 353-367 (0.01), } \\
\text { AD 381-657 }(0.95)\end{array}$ & 519 \\
\hline 41SM273 & Beta-173092 & $1590 \pm 90$ & -25.9 & $1570 \pm 90$ & AD 405-590 (0.68) & $\begin{array}{l}\text { AD } 259-295(0.03) \text {, } \\
\text { AD 322-648 (0.92) }\end{array}$ & 482 \\
\hline 41SM273 & Beta-173095 & $1640 \pm 40$ & -26.9 & $1610 \pm 40$ & $\begin{array}{l}\text { AD } 408-465(0.35) \text {, } \\
\text { AD } 482-533(0.33)\end{array}$ & $\begin{array}{l}\text { AD 348-369 (0.03), } \\
\text { AD 379-547 (0.93) }\end{array}$ & 463 \\
\hline 41SM273 & Beta-173090 & $1680 \pm 40$ & -24.4 & $1690 \pm 40$ & $\begin{array}{l}\text { AD } 261-280(0.11), \\
\text { AD 326-410 }(0.58)\end{array}$ & AD $249-426(0.95)$ & 353 \\
\hline 41SM273 & Beta-157991 & $1710 \pm 40$ & -24.9 & $1710 \pm 40$ & $\begin{array}{l}\text { AD 259-296 (0.23), } \\
\text { AD 322-388 (0.45) }\end{array}$ & AD $241-415(0.95)$ & 332 \\
\hline 41SM273 & Beta-182401 & $1710 \pm 40$ & -25.1 & $1710 \pm 40$ & $\begin{array}{l}\text { AD 259-296 (0.23), } \\
\text { AD 322-388 (0.45) }\end{array}$ & AD $241-415(0.95)$ & 332 \\
\hline 41SM273 & Beta-173097 & $1720 \pm 40$ & -25.1 & $1720 \pm 40$ & $\begin{array}{l}\text { AD } 257-300(0.28) \text {, } \\
\text { AD } 318-382(0.40)\end{array}$ & AD 235-414 (0.95) & 321 \\
\hline 41SM273 & Beta-182402 & $1810 \pm 40$ & -25.0 & $1810 \pm 40$ & AD 136-243 (0.68) & $\begin{array}{l}\text { AD } 86-109(0.03), \\
\text { AD 120-264 (0.80), } \\
\text { AD 275-334 (0.13) }\end{array}$ & 201 \\
\hline 41SY041 & Beta-97897 & $960 \pm 70$ & -6.0 & $1270 \pm 70$ & $\begin{array}{l}\text { AD 664-782 (0.58), } \\
\text { AD 789-810 (0.08), } \\
\text { AD 848-855 (0.02) }\end{array}$ & $\begin{array}{l}\text { AD 645-896 (0.94), } \\
\text { AD 924-938 (0.01) }\end{array}$ & 755 \\
\hline 41TT370 & Beta-48882 & $2140 \pm 100$ & 一 & $2140 \pm 100$ & $\begin{array}{l}356-286 \mathrm{BC}(0.18), \\
234-50 \mathrm{BC}(0.50)\end{array}$ & $\begin{array}{l}394 \text { BC-AD } 29(0.95), \\
\text { AD 39-50 }(0.01)\end{array}$ & -183 \\
\hline 41TT372 & Beta-70994 & $1290 \pm 50$ & -26.4 & $1270 \pm 50$ & AD 670-778 (0.68) & AD 660-875 (0.95) & 744 \\
\hline 41TT372 & Beta-71006 & $1330 \pm 60$ & -26.1 & $1310 \pm 60$ & $\begin{array}{l}\text { AD } 657-728(0.46) \text {, } \\
\text { AD 736-772 (0.22) }\end{array}$ & AD 635-876 (0.95) & 718 \\
\hline 41TT372 & Beta-71000 & $1420 \pm 60$ & -26.8 & $1390 \pm 60$ & AD 595-682 (0.68) & $\begin{array}{l}\text { AD 545-724 (0.89), } \\
\text { AD 739-771 (0.06) }\end{array}$ & 643 \\
\hline
\end{tabular}


Table $2{ }^{14} \mathrm{C}$ dates for the east Texas Woodland period. ${ }^{\mathrm{a}}$ (Continued)

\begin{tabular}{|c|c|c|c|c|c|c|c|}
\hline Trinomial $^{\mathrm{b}}$ & Sample nr & Raw age & $\begin{array}{l}\delta^{13} \mathrm{C} \\
(\%)\end{array}$ & $\begin{array}{l}\text { Corrected } \\
{ }^{14} \mathrm{C} \text { age }\end{array}$ & $1 \sigma$ age range & $2 \sigma$ age range & $\begin{array}{l}\text { Me- } \\
\text { dian }\end{array}$ \\
\hline 41TT372 & Beta-70995 & $1800 \pm 60$ & -25.3 & $1800 \pm 60$ & $\begin{array}{l}\text { AD 131-259 (0.58), } \\
\text { AD 295-322 }(0.10)\end{array}$ & AD 81-382 (0.95) & 220 \\
\hline 41TT409 & Beta-64984 & $1730 \pm 60$ & -30.4 & $1640 \pm 60$ & $\begin{array}{l}\text { AD 340-442 }(0.47) \text {, } \\
\text { AD } 454-461(0.02), \\
\text { AD } 484-533(0.19)\end{array}$ & AD $255-548(0.95)$ & 413 \\
\hline 41TT409 & Beta-64985 & $1710 \pm 60$ & -25.5 & $1700 \pm 60$ & $\begin{array}{l}\text { AD } 257-302(0.21) \text {, } \\
\text { AD } 316-410(0.47)\end{array}$ & $\begin{array}{l}\text { AD 172-193 }(0.01) \text {, } \\
\text { AD 211-465 }(0.90) \\
\text { AD 482-533(0.05) }\end{array}$ & 340 \\
\hline 41TT550 & Beta-70989 & $2080 \pm 60$ & -27.0 & $2050 \pm 60$ & $\begin{array}{l}162-131 \text { BC }(0.12), \\
119 \text { BC-AD } 5(0.56)\end{array}$ & $\begin{array}{l}342-327 \text { BC (0.01), } \\
204 \text { BC-AD } 74(0.94)\end{array}$ & -70 \\
\hline 41TT653 & Beta-117272 & $1870 \pm 50$ & -23.2 & $1900 \pm 50$ & $\begin{array}{l}\text { AD 29-38 (0.03), } \\
\text { AD 51-140(0.54), } \\
\text { AD 151-170(0.06), } \\
\text { AD 194-210(0.05) }\end{array}$ & AD 3-236 (0.95) & 107 \\
\hline 41TT847 & Beta-242371 & $1360 \pm 40$ & -26.6 & $1330 \pm 40$ & $\begin{array}{l}\text { AD } 652-695(0.50) \text {, } \\
\text { AD } 701-707(0.04), \\
\text { AD } 748-765(0.14)\end{array}$ & AD $645-772(1.00)$ & 686 \\
\hline 41TT865 & Beta-242373 & $2180 \pm 40$ & -26.9 & $2150 \pm 40$ & $\begin{array}{l}351-299 \text { BC }(0.24), \\
228-223 \text { BC }(0.02), \\
210-151 \text { BC }(0.32), \\
140-112 \text { ВC }(0.11)\end{array}$ & $\begin{array}{l}358-277 \mathrm{BC}(0.31), \\
259-87 \mathrm{BC}(0.65), \\
78-55 \mathrm{BC}(0.04)\end{array}$ & -196 \\
\hline 41UR077 & Beta-166910 & $1480 \pm 50$ & -25.5 & $1470 \pm 50$ & AD 558-640 (0.68) & $\begin{array}{l}\text { AD 460-480, } \\
\text { AD 520-660 }\end{array}$ & 589 \\
\hline 41UR077 & UGA-12983 & $1830 \pm 40$ & -24.4 & $1840 \pm 40$ & AD $130-226(0.68)$ & $\begin{array}{l}\text { AD 75-255 }(0.95) \\
\text { AD 305-313 }(0.01)\end{array}$ & 174 \\
\hline 41UR077 & UGA-12984 & $1840 \pm 40$ & -24.8 & $1840 \pm 40$ & AD $130-226(0.68)$ & $\begin{array}{l}\text { AD } 75-255(0.95), \\
\text { AD } 305-313(0.01)\end{array}$ & 174 \\
\hline 41UR077 & UGA-12971 & $2190 \pm 40$ & -25.1 & $2190 \pm 40$ & $\begin{array}{l}358-281 \text { ВC }(0.42), \\
258-243 \text { ВC }(0.06), \\
236-197 \text { ВC }(0.20)\end{array}$ & $\begin{array}{l}383-164 \text { ВC }(0.95), \\
128-122 \text { ВC }(0.01)\end{array}$ & -278 \\
\hline 41UR133 & Beta-117743 & - & - & $2250 \pm 60$ & $\begin{array}{l}391-350 \text { BC (0.21), } \\
304-209 \text { BC }(0.47)\end{array}$ & 406-170 BC (0.95) & -288 \\
\hline 41WD495 & Tx-3045 & $1760 \pm 50$ & - & $1760 \pm 64$ & $\begin{array}{l}\text { AD } 180-187(0.02), \\
\text { AD } 214-382(0.66)\end{array}$ & $\begin{array}{l}\text { AD 93-97 }(0.00), \\
\text { AD 125-417 }(0.95)\end{array}$ & 275 \\
\hline
\end{tabular}

${ }^{a}$ Missing values in the Sample $\mathrm{nr}$, Raw age, and $\delta^{13} \mathrm{C}$ columns were not reported in technical reports.

b"Trinomial" refers to the Smithsonian trinomial numbering system where the state is indicated by a number ranging from 1 to 50 , the county by $2-3$ capitals, and the site within the county is represented by a number ranging from 1 to infinity.

To facilitate the statistical analysis, median ages were used to calculate the frequency of samples within each of the 5 major river basins in east Texas, and that information was used to inform a discussion of the average median age of Woodland sites in each river basin. To conclude the statistical analysis, a kernel density plot was created to explore potential populations within the sample of median ages.

Subsequent modifications include the addition of the North American Datum, UTM zone, UTM northing, UTM easting, and river basin. The river basins used in the analysis are the Red River basin (RRB), Sulphur River basin (SRB), Cypress Creek basin (CCB), Sabine River basin (SaRB), and the Neches River basin (NRB), as currently defined by the Texas Natural Resources Information System (TNRIS 2012) (Figure 1).

\section{${ }^{14} \mathrm{C}$ Date Combination}

The date combination process assumes that if all assays collected at a particular site draw carbon from the same reservoir, then they should have the same underlying $\mathrm{F}^{14} \mathrm{C}$ value and can be combined prior to calibration (Bronk Ramsey 2008). The measurements have Gaussian uncertainty distribu- 


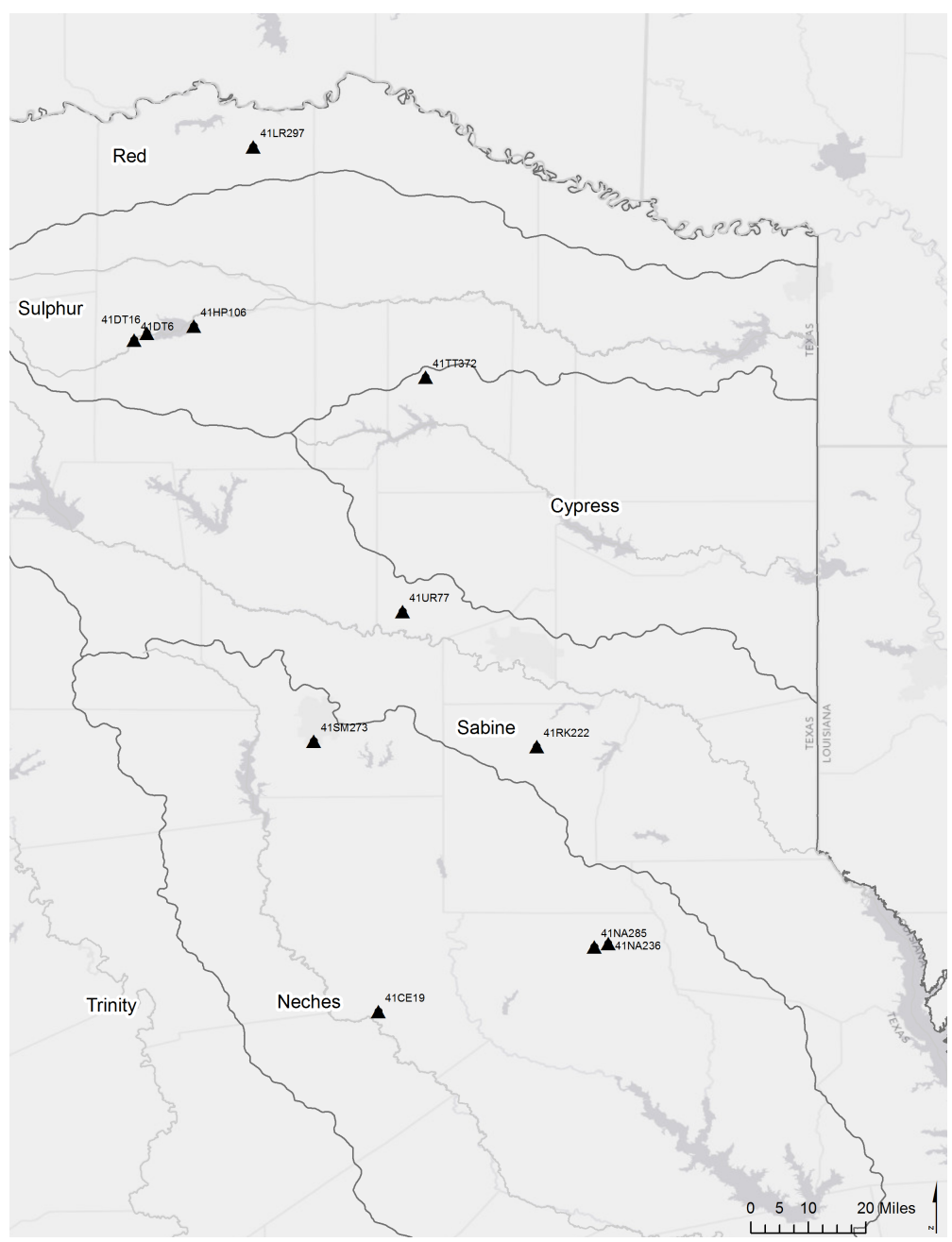

Figure 1 Map of east Texas river basins and the 11 Woodland period sites with 4 or more ${ }^{14} \mathrm{C}$ dates.

tions, and $\chi^{2}$ was used to test the assumption that all ratios are the same to reveal whether compelling evidence exists - at the $95 \%$ confidence level - that dates cannot be related to the same event (Bronk Ramsey 2008). Each site-specific figure provides the SPDs, calibrated age range for combined assays, and all dates utilized to inform these results.

Although ${ }^{14} \mathrm{C}$ determinations are most often represented in the form $A \pm E$ where $A$ is the ${ }^{14} \mathrm{C}$ estimate (BP) and $E$ represents the standard deviation, the method of date combination can be used to create a new ${ }^{14} \mathrm{C}$ determination from multiple assays often with the ancillary benefit of a decrease in the standard deviation (Ward and Wilson 1978). To test whether a series of ${ }^{14} \mathrm{C}$ determinations are consistent, the pooled mean is calculated by way of $A_{p}$, where

$$
A_{p}=\left(\sum_{1}^{n} A_{i} / E_{i}^{2}\right) /\left(\sum_{1}^{n} 1 / E_{i}^{2}\right)
$$


followed by the test statistic, $T$, where

$$
T=\sum_{1}^{n}\left(A_{i}-A_{p}\right)^{2} / E_{i}^{2}
$$

the latter of which illustrates a $\chi^{2}$ distribution on $n-1$ degrees of freedom under the null hypothesis (see Clark 1975:252; Ward and Wilson 1978:21).

Provided that the ${ }^{14} \mathrm{C}$ determinations are found not to be significantly different, they can then be combined with the pooled age as $A_{p}$ given by $i$, and the variance given by

$$
V\left(A_{p}\right)=\left(\sum_{1}^{n} 1 / E_{i}^{2}\right)^{-1}
$$

(Ward and Wilson 1978:21), which is a process accessible in OxCal by way of the R_Combine function. Once combined with $\mathrm{R}$ CCombine, a new date range, standard deviation, and median age is provided for the combined samples (Figure 2). Within the framework of this study, the new date range replaces the combined dates and was employed within the revised SPD, while the new median date was used for statistical analyses.

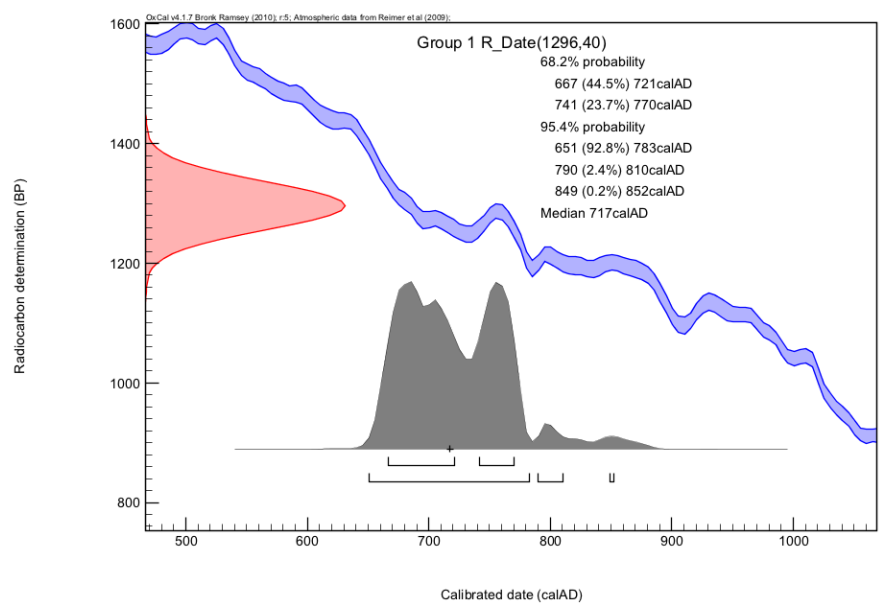

Figure 2 Calibrated results from the R_Combine function for 41DT16 Group 1

\section{Calibration Curve}

Conventional ${ }^{14} \mathrm{C}$ dates used within the framework of this study were recalibrated using IntCal09 (Figure 3). The curve serves as the basis for date calibration and can aid the process of archaeological interpretation by highlighting temporal zones with reversals and plateaus. Within the span of time assigned to the east Texas Woodland period (500 BC-AD 800), the curve can be seen to have 3 notable reversals of varying degrees (370-220 BC, AD 240-340, and AD 680-780). There are also 3 plateaus within the curve (500-420 BC, AD 140-210, and AD 430-540). While this does not produce clues regarding human behaviors, it does help to clarify why - even after combinationsome date ranges have longer spans of probability for the calibrated date range. 


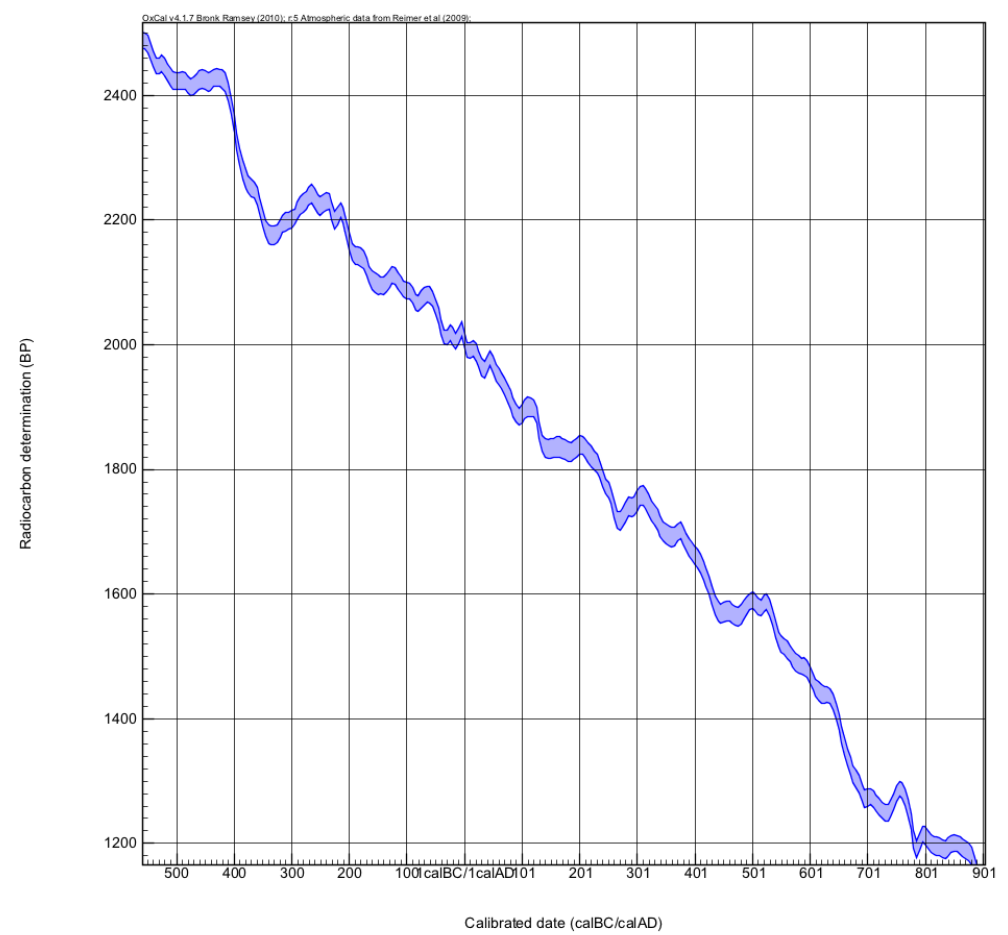

Figure 3 IntCal09 ${ }^{14} \mathrm{C}$ calibration curve for the east Texas Woodland period

\section{THE WOODLAND SAMPLE}

The Woodland sites with 4 or more ${ }^{14} \mathrm{C}$ assays include George C Davis (41CE19), Tick (41DT6), Spike (41DT16), Hurricane Hill (41HP106), Stallings Ranch (41LR297), Naconiche Creek (41NA236), Boyette (41NA285), Herman Ballew (41RK222), Broadway (41SM273), 41TT372, and 41UR77. The number of ${ }^{14} \mathrm{C}$ samples from each site is heavily biased by the variable mitigation strategies and research designs used in archaeological practice. The ${ }^{14} \mathrm{C}$ samples from these sites are refined through date combination, where the results of date combination replaced the original assays, and then incorporated with the remaining 42 samples used in this analysis.

\section{CE19 (George C Davis Site)}

The Woodland period ${ }^{14} \mathrm{C}$ dates for the George C Davis site $(n=7)$ have been combined into 2 groups (Figure 4). Group 1 consists of Tx-1223, -919, -105, -674, and -3312. Group 2 comprises Tx3695 and a reported conventional ${ }^{14} \mathrm{C}$ age with an assay number that was not reported. The $2 \sigma$ age ranges for the groups, AD 358-544 for Group 2 and AD 616-773 for Group 1, indicate a possible occupational hiatus of $72{ }^{14} \mathrm{C}$ yr. Occupation periods for the $2{ }^{14} \mathrm{C}$ groups span 186 and $157 \mathrm{cal}{ }^{14} \mathrm{C}$ yr, respectively.

\section{DT6 (Tick Site)}

All ${ }^{14} \mathrm{C}$ dates from the Tick site $(n=5)$ were unable to be combined via the OxCal $X$ test (Figure 5). Only 3 assays (Beta-51364, -51366, and -51367) were combined into Group 1, leaving the remaining assays (Beta-51368 and -51365 ) to populate the balance of the summed probability distribution. This site represents the singular example of overlapping occupations between AD 660-667, and the ${ }^{14} \mathrm{C}$ assays indicate a continuous, but probably episodic, occupation of $831 \mathrm{cal}{ }^{14} \mathrm{C} \mathrm{yr}$. 


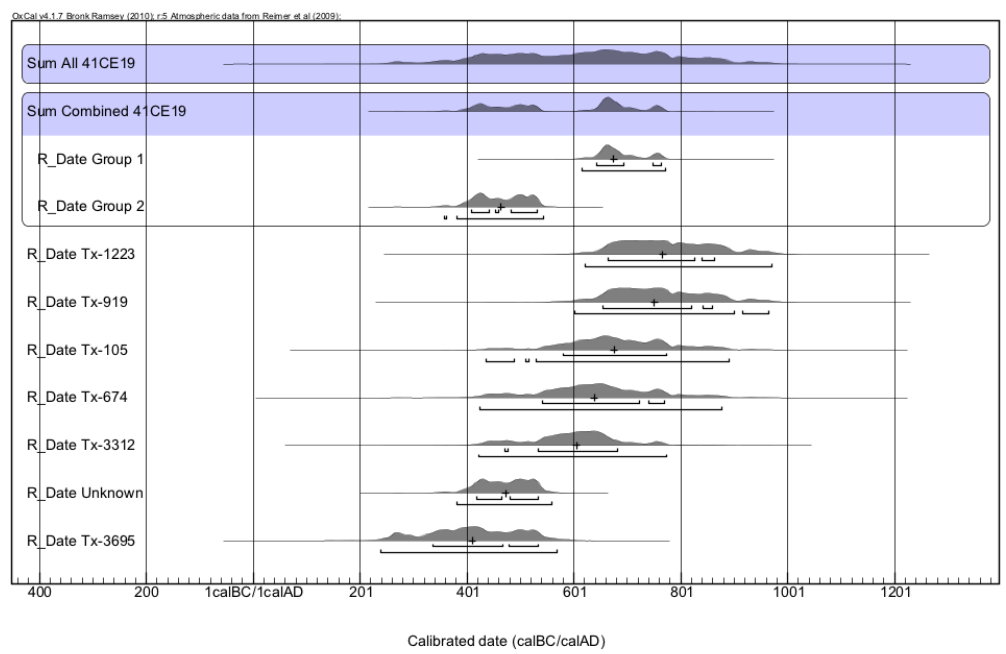

Figure 4 Combined $1 \sigma$ and $2 \sigma$ date ranges with median age illustrated, normal and combined summed probability distribution for ${ }^{14} \mathrm{C}$ dates from the George $\mathrm{C}$ Davis site (41CE19).

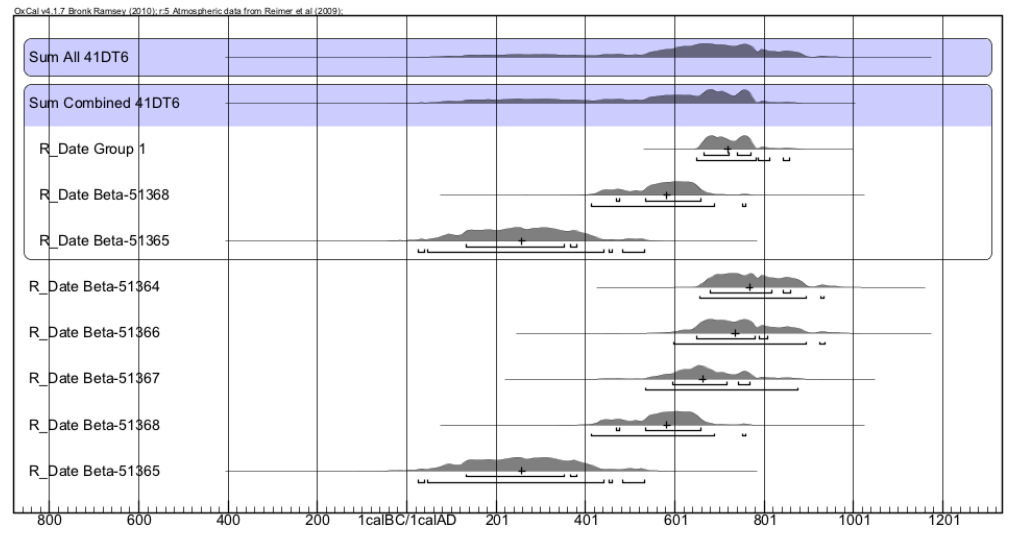

Calibrated date (calBC/calAD)

Figure 5 Combined $1 \sigma$ and $2 \sigma$ date ranges with median age illustrated, normal and combined summed probability distribution for ${ }^{14} \mathrm{C}$ dates from the Tick site (41DT6).

\section{DT16 (Spike Site)}

There are $6{ }^{14} \mathrm{C}$ assays from the Spike site, 3 of which were combined, resulting in a final sample of $3{ }^{14} \mathrm{C}$ ages. Group 1 consists of Beta-52245 and -52244 , and Group 2 includes Beta-52242, -52241 , and -51372 (Figure 6). Beta-51371 was not able to be combined with the 2 other groups. Beta-51371 ranges from $336 \mathrm{BC}-\mathrm{AD} 21$, the Group 2 range is $\mathrm{AD} 434-574$, and Group 1 ranges from $\mathrm{AD} 667-$ 770 , indicating a temporal hiatus of $413 \mathrm{cal}{ }^{14} \mathrm{C}$ yr between Beta-51371 and Group 2, and $93 \mathrm{cal}{ }^{14} \mathrm{C}$ yr between Group 2 and Group 1. Occupational periods span 357, 140, and $103 \mathrm{cal}{ }^{14} \mathrm{C} \mathrm{yr}$, respectively. 


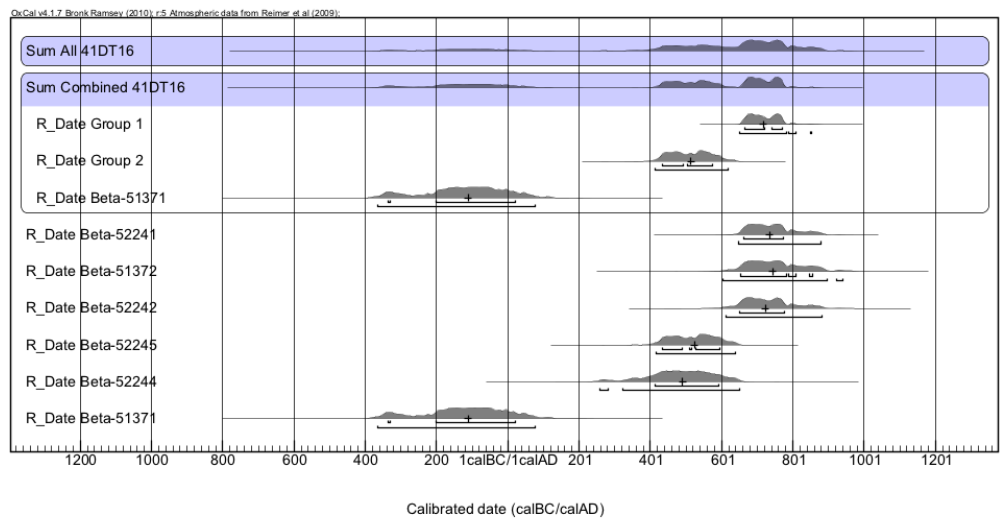

Figure 6 Combined $1 \sigma$ and $2 \sigma$ date ranges with median age illustrated, normal and combined summed probability distribution for ${ }^{14} \mathrm{C}$ dates from the Spike site (41DT16).

\section{HP106 (Hurricane Hill Site)}

There are $7{ }^{14} \mathrm{C}$ dates from the Woodland period occupation at the Hurricane Hill site. Six of these (Beta-82913, -82914, -82915, -85866, -82917, and -85868) comprise Group 1, while a single and much earlier assay (Beta-85867) was unable to be combined with the other dates (Figure 7). The Beta-85867 date ranges from 398-202 BC and Group 1 dates indicate an occupation ranging from $\mathrm{AD} 85-235$; there is a temporal hiatus of $287 \mathrm{cal}{ }^{14} \mathrm{C}$ yr between the 2 occupations. Occupational periods span 150 and $196 \mathrm{cal}{ }^{14} \mathrm{C}$ yr, respectively.

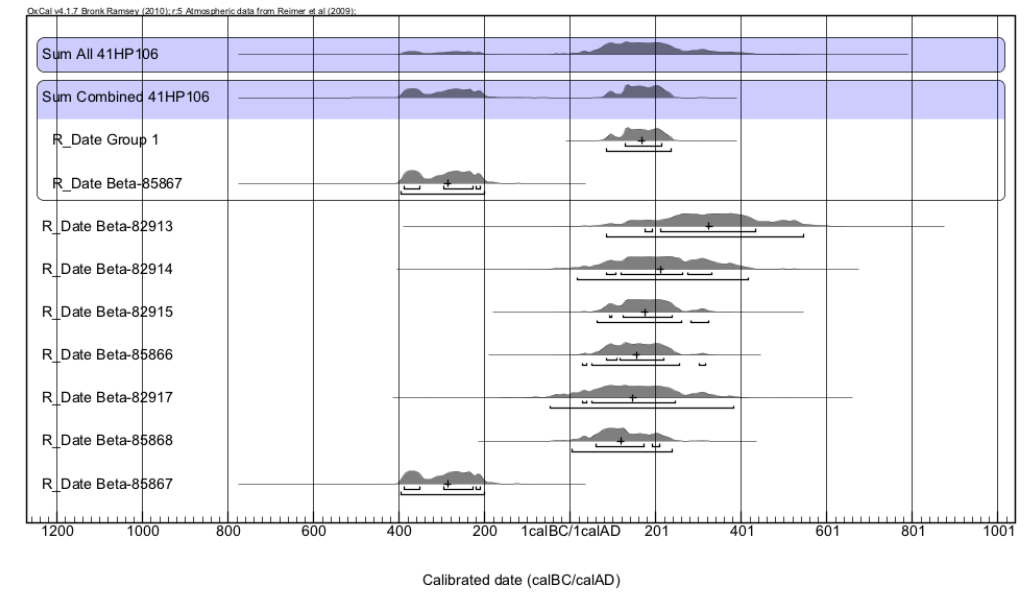

Figure 7 Combined $1 \sigma$ and $2 \sigma$ date ranges with median age illustrated, normal and combined summed probability distribution for ${ }^{14} \mathrm{C}$ dates from the Hurricane Hill site (41HP106).

\section{LR297 (Stallings Ranch Site)}

Only 2 of the ${ }^{14} \mathrm{C}$ dates from the Stallings Ranch site $(n=4)$ were combined. The assays with the latest (Beta-239524) and the earliest (Beta-237678) calibrated age ranges are plotted individually, and Group 1 consists of Beta-237680 and -237677 (Figure 8). There are 3 possible occupations at Stallings Ranch, the first (Beta-237678) ranging from 736-211 BC, with a peak distribution at $400 \mathrm{BC}$, Group 1 from AD 432-619, and AD 656-870 for Beta-239524. This indicates a $643 \mathrm{cal}{ }^{14} \mathrm{C}$ yr hiatus 
between the first and second occupations, and a $37 \mathrm{cal}{ }^{14} \mathrm{C}$ yr hiatus between the second and third. Occupational periods span 525,187 , and $214 \mathrm{cal}{ }^{14} \mathrm{C}$ yr, respectively.

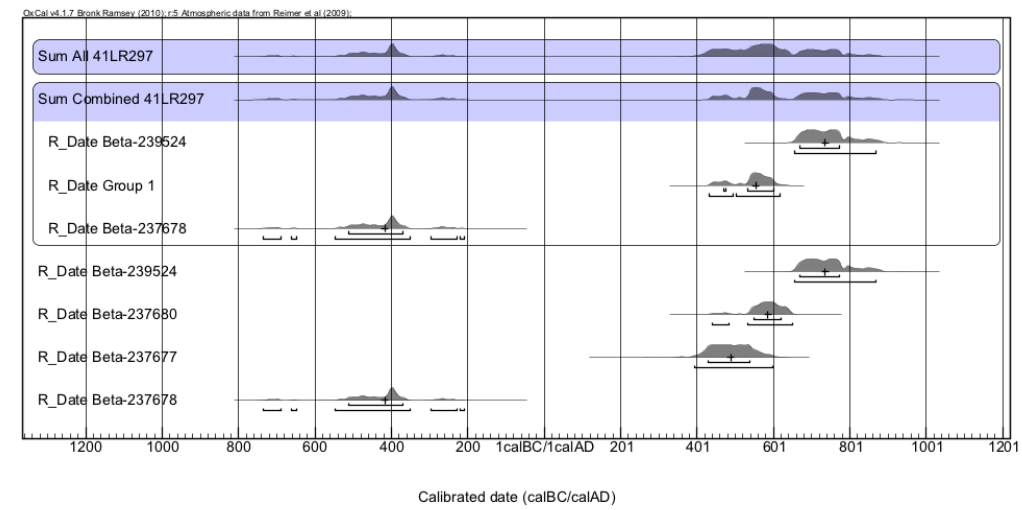

Figure 8 Combined $1 \sigma$ and $2 \sigma$ date ranges with median age illustrated, normal and combined summed probability distribution for ${ }^{14} \mathrm{C}$ dates from the Stallings Ranch site (41LR297).

\section{NA236 (Naconiche Creek Site)}

The ${ }^{14} \mathrm{C}$ dates from the Naconiche Creek site $(n=9)$ were combined into 2 groups, excluding only a single and older assay (Beta-151098) (Figure 9). Group 1 encompasses the Beta-183857, -203667, -204783 , and -203666 samples. Group 2 consists of the samples Beta-204782, -203669, -151097, and -203668. Beta-151098 spans the period from 735-382 BC, Group 2 ranges from AD 56-214, and Group 1 extends from AD 541-636, indicating an occupational hiatus of $438 \mathrm{cal}{ }^{14} \mathrm{C}$ yr between the first and second occupations, and $327 \mathrm{cal}{ }^{14} \mathrm{C}$ yr between the second and third occupations. Occupational periods span 353,158 , and $95 \mathrm{cal}^{14} \mathrm{C}$ yr, respectively.

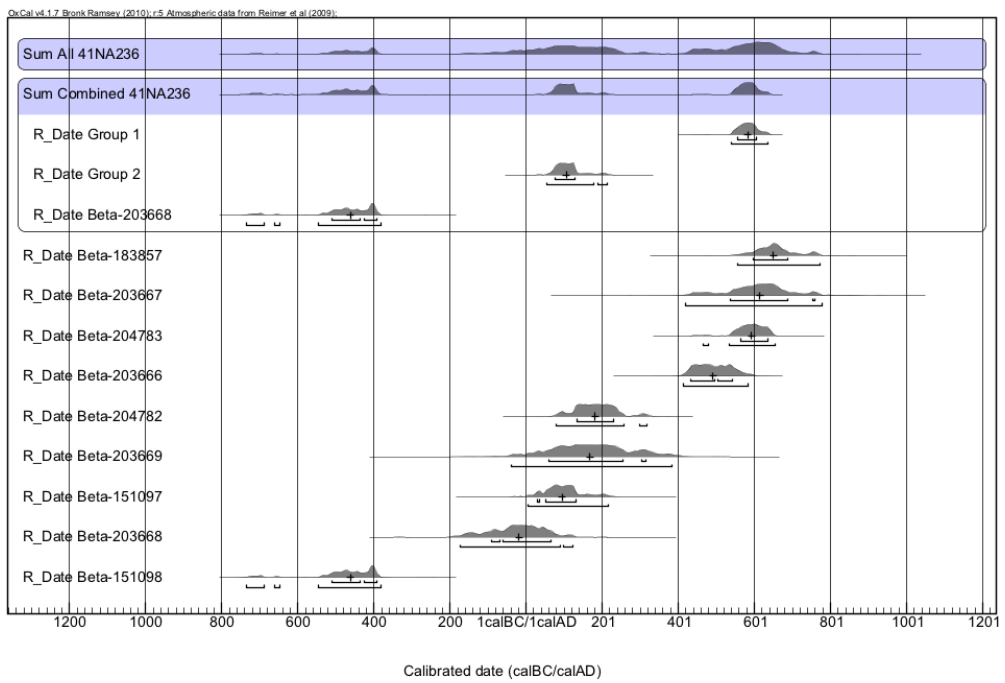

Figure 9 Combined $1 \sigma$ and $2 \sigma$ date ranges with median age illustrated, normal and combined summed probability distribution for ${ }^{14} \mathrm{C}$ dates from the Naconiche Creek site (41NA236). 


\section{NA285 (Boyette Site)}

${ }^{14} \mathrm{C}$ dates from the Boyette site $(n=6)$ were combined into 2 groups with a single uncombined exception (Beta-221420) (Figure 10). Group 1 comprises 3 assays (Beta-221421, -201990, and -204786), while Group 2 consists of 2 assays (Beta-151112 and -201989). Group 2 dates from 197-107 BC, Beta-221420 dates from AD 425-534, and Group 1 ranges from AD 685-770, indicating a temporal hiatus of $532 \mathrm{cal}{ }^{14} \mathrm{C}$ yr between Group 2 and Beta-221420, and $151 \mathrm{cal}{ }^{14} \mathrm{C}$ yr between Beta-221420 and Group 1. Occupational periods span 90,109 , and $85 \mathrm{cal}{ }^{14} \mathrm{C}$ yr, respectively.

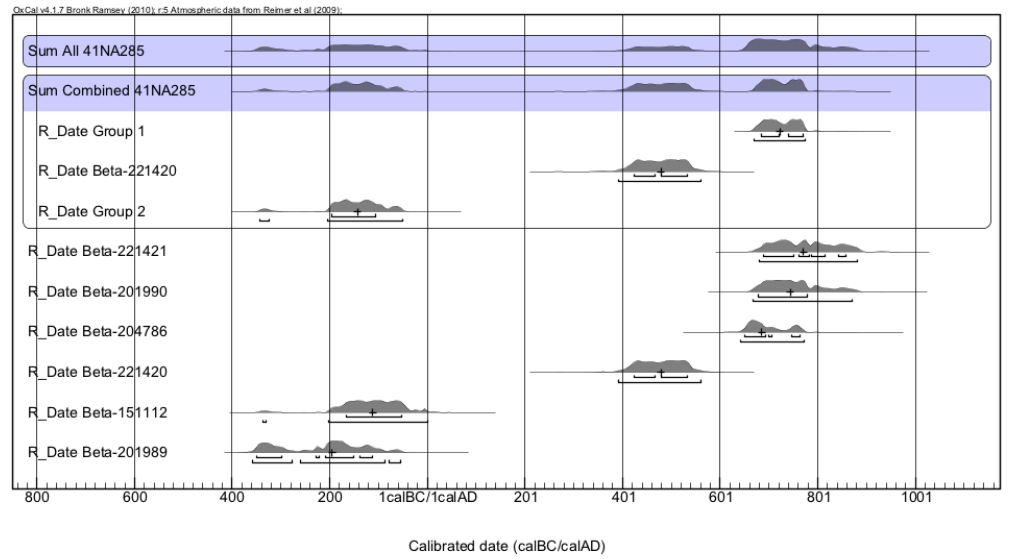

Figure 10 Combined $1 \sigma$ and $2 \sigma$ date ranges with median age illustrated, normal and combined summed probability distribution for ${ }^{14} \mathrm{C}$ dates from the Boyette site (41NA285).

\section{RK222 (Herman Ballew Site)}

The ${ }^{14} \mathrm{C}$ dates from the Herman Ballew site $(n=6)$ were combined into 1 group $(n=5)$, excluding only a single and younger assay (Beta-60093) (Figure 11). Group 1 consists of Beta-60094, -72776, $-72770,-72778$, and -72771 . The $2 \sigma$ age range for Group 1 is AD 54-221, and AD 439-772 is the calibrated age range for the Beta-60093 assay. This indicates a possible hiatus of $218 \mathrm{cal}{ }^{14} \mathrm{C} \mathrm{yr}$ between occupations. Occupational periods span 167 and $333 \mathrm{cal}{ }^{14} \mathrm{C} \mathrm{yr}$, respectively.

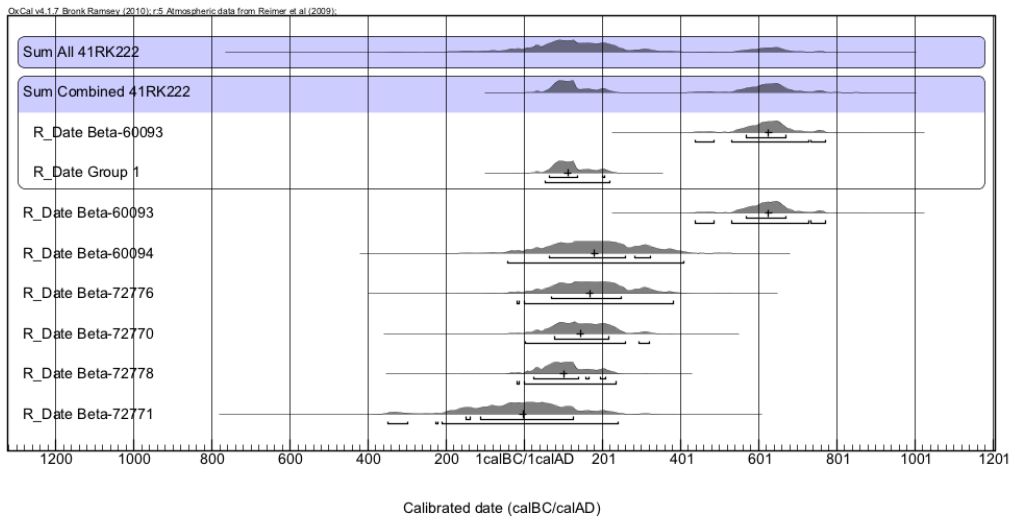

Figure 11 Combined $1 \sigma$ and $2 \sigma$ date ranges with median age illustrated, normal and combined summed probability distribution for ${ }^{14} \mathrm{C}$ dates from the Herman Ballew site (41RK222). 


\section{SM273 (Broadway Site)}

The $13{ }^{14} \mathrm{C}$ dates from the Woodland period occupation at the Broadway site were combined into 3 groups (Figure 12). Group 1 consists of 2 assays (Beta-157990 and -173089), Group 2 has 6 assays (Beta-154860,-157989, -173091, -154857, -173092, and -173095), and Group 3 has 5 assays (Beta173090, -157991, -182401, -173097, and -182402). Group 3 dates from AD 257-344, Group 2 has an age range from $\mathrm{AD} 442-574$, and Group 1 dates from $\mathrm{AD}$ 685-771, indicating a temporal hiatus of 98 cal ${ }^{14} \mathrm{C}$ yr between Group 3 and Group 2, and $111 \mathrm{cal}{ }^{14} \mathrm{C}$ yr between Group 2 and Group 1. Occupational periods span 87,132 , and 86 cal ${ }^{14} \mathrm{C}$ yr, respectively.

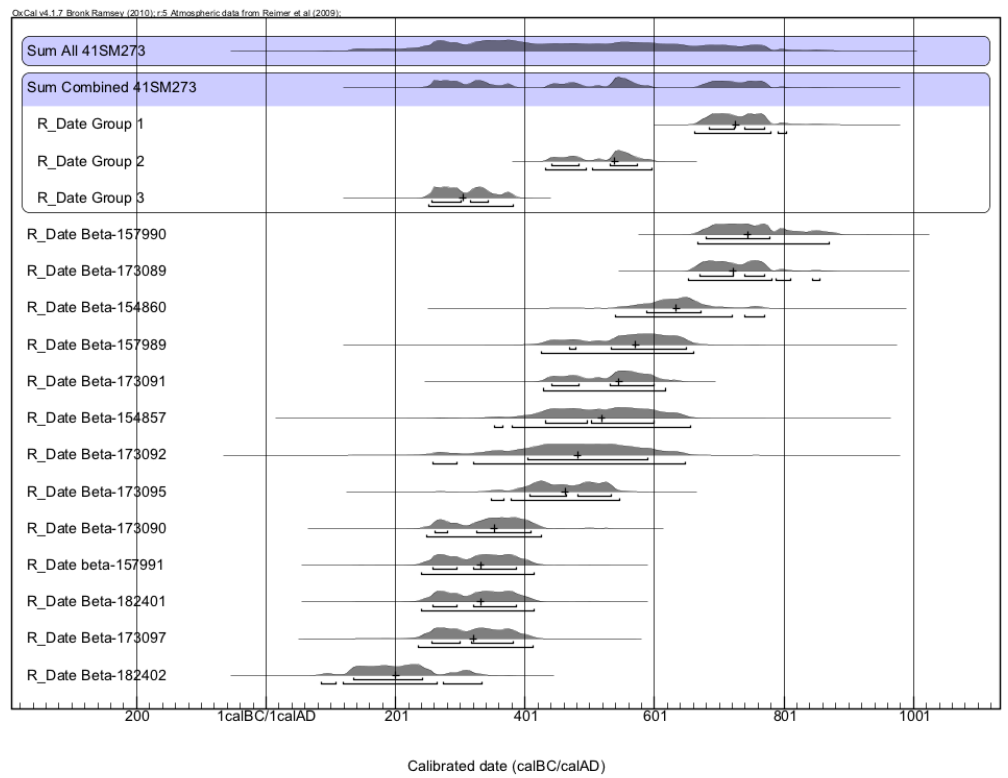

Figure 12 Combined $1 \sigma$ and $2 \sigma$ date ranges with median age illustrated, normal and combined summed probability distribution for ${ }^{14} \mathrm{C}$ dates from the Broadway site (41SM273).

\section{TT372}

${ }^{14} \mathrm{C}$ dates for 41TT372 $(n=4)$ were combined into a single group $(n=3)$, excluding 1 earlier assay (Beta-70995) (Figure 13). Group 1 consists of Beta-70994, -71006, and -71000. The early assay (Beta-70995) ranges from AD 131-322, and Group 1 dates from AD 659-765, indicating a temporal hiatus of $337 \mathrm{cal}{ }^{14} \mathrm{C}$ yr between occupations. Occupational periods span 191 and $106 \mathrm{cal}{ }^{14} \mathrm{C} \mathrm{yr}$, respectively.

\section{UR77}

${ }^{14} \mathrm{C}$ dates from $41 \mathrm{UR} 77(n=4)$ were combined into a single group with 2 dates, and there are 2 younger and older exclusions (Beta-166910 and UGA-12971, respectively) that could not be grouped (Figure 14). Group 1 consists of UGA-12983 and UGA-12984. The $2 \sigma$ age range for UGA12971 is 358-197 BC, for Group 1 it is AD 133-215, and for Beta-166910 the age range is AD 558640. This indicates a temporal hiatus of $330 \mathrm{cal}{ }^{14} \mathrm{C}$ yr between the first and second occupations, and $343 \mathrm{cal}{ }^{14} \mathrm{C}$ yr between the second and third occupations. Occupational periods span 161, 82, and 82 cal ${ }^{14} \mathrm{C}$ yr, respectively. 


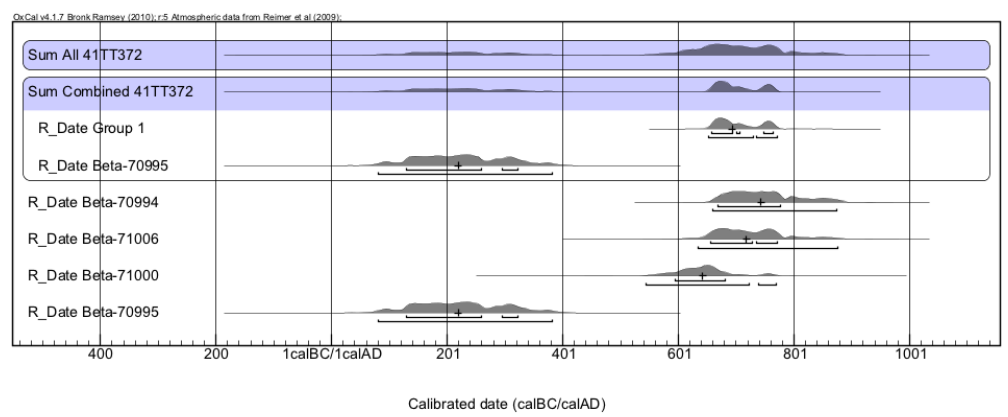

Figure 13 Combined $1 \sigma$ and $2 \sigma$ date ranges with median age illustrated, normal and combined summed probability distribution for ${ }^{14} \mathrm{C}$ dates from $41 \mathrm{TT} 372$.

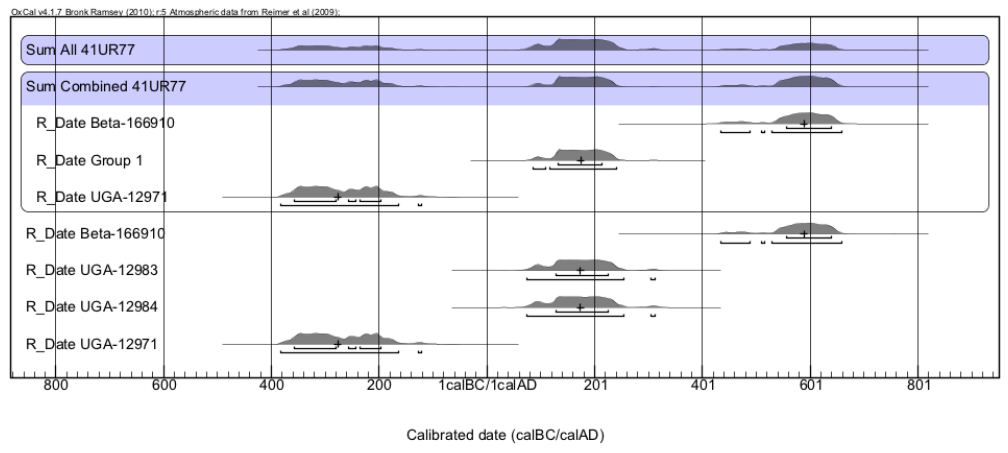

Figure 14 Combined $1 \sigma$ and $2 \sigma$ date ranges with median age illustrated, normal and combined summed probability distribution for ${ }^{14} \mathrm{C}$ dates from $41 \mathrm{UR} 77$.

\section{RESULTS}

Through the date combination (R_Combine) process, the number of assays decreased from 127 to 85 , which lowered the standard deviation for the combined group while reducing the number of median ages to be used in the statistical analysis. Summed probability distributions were then produced for each site with 4 or more dates to better illustrate when diffuse and discrete periods of occupation can be identified.

The SPD for the whole of the Woodland period was created using the revised (i.e. combined from sites with $4{ }^{14} \mathrm{C}$ assays) sample of $85{ }^{14} \mathrm{C}$ dates from 51 archaeological sites in east Texas (Figure 15). This representation of these data is not biased by sites with larger numbers of samples due to the date combination process. While not discussed here, those sites with $<4{ }^{14} \mathrm{C}$ assays that conformed to methodological constraints were included in the Woodland SPD.

\section{Temporal Considerations}

Incorporating these results into a revised Woodland sample reduces the number of ${ }^{14} \mathrm{C}$ assays from 127 to 85 . The final sample represents Woodland components from 51 archaeological sites in the Red River ( $n=7$ dates), Sulphur River $(n=20)$, Cypress Creek $(n=10)$, Sabine River $(n=20)$, and Neches River $(n=26)$ basins (Figure 16). The sample was sorted by median age, illustrating that the dates for Woodland period sites - when ordered by appearance - are oldest in the Red River basin (AD 134), followed by Cypress Creek (AD 202), Sulphur (AD 251), Sabine River (AD 296), and Neches River basins (AD 312) (Figure 16). 


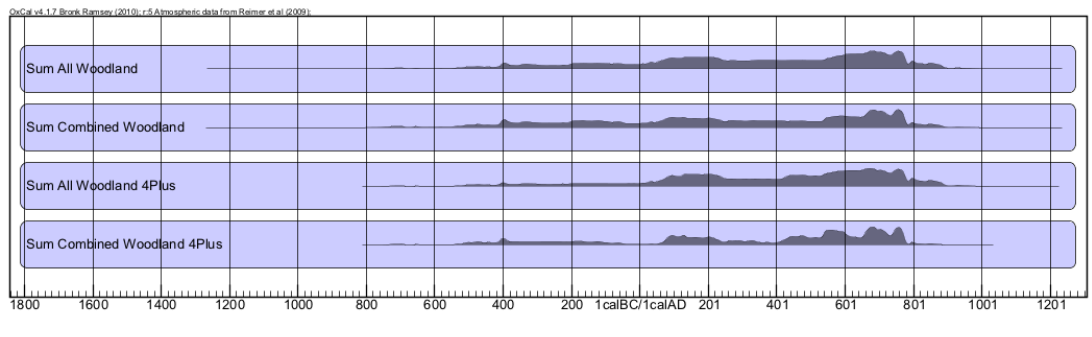

Calibrated date (calBC/calAD)

Figure 15 Summed probability distributions contrasting all and combined dates from the entirety of the sample, and from those sites with $4{ }^{14} \mathrm{C}$ dates.
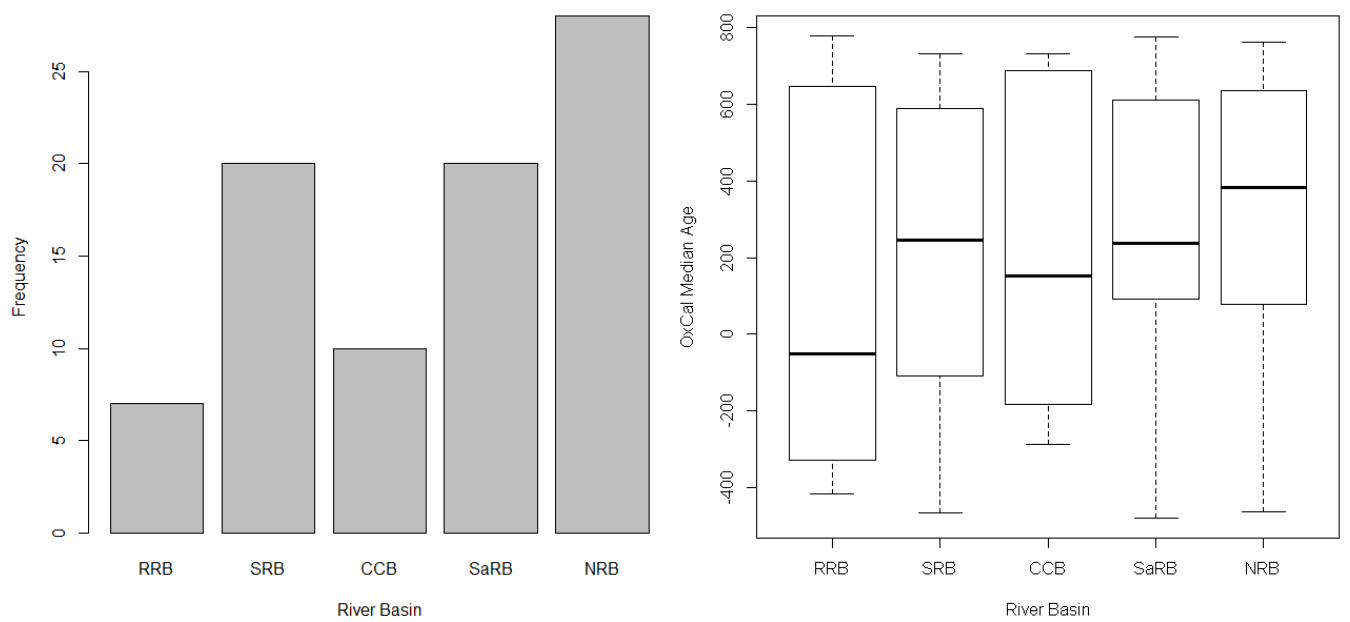

Figure 16 Frequency of samples (left) and boxplot of median ages (right) by river basin

A summed probability distribution was calculated for the entirety of the Woodland period, and illustrates the temporal placement of Woodland components from key sites in east Texas (Figure 17). Although the number of sites is small, they highlight a possible temporal hiatus of nearly $400 \mathrm{yr}$ in the Red River basin, and another of nearly $200 \mathrm{yr}$ in the Cypress Creek basin, both of which appear here on the basis of data from 1 site in each river basin. The remaining peaks correlate with populations from the kernel density plot, and they illustrate a small peak in the Red River basin around $400 \mathrm{BC}$ followed by slight increases in the dates from the Sulphur, Cypress, and Sabine basins around $200 \mathrm{BC}$. This is prior to a 200 -yr peak in dates from the Sulphur and Sabine River basins for AD 50-220, after which a marked increase occurs in the number of dated Woodland sites for the Sulphur, Cypress, Sabine, and Neches River basins from AD 600-800.

The temporal character of Woodland occupations from the 11 sites has been dissected and then reassembled to illustrate the temporal range of occupations and hiatuses for each (Table 3 ). The diversity of occupational length within the sample ranges from an average of $95-831 \mathrm{cal}{ }^{14} \mathrm{C} \mathrm{yr}$, with breaks of $0-382 \mathrm{cal}{ }^{14} \mathrm{C}$ yr. Of the 11 sites, 1 may have been continually-if episodically-occupied (41DT6), 4 have 2 discretely dated occupational events (41HP106, 41TT372, 41RK222, and 41CE19), and 6 have 3 discretely dated occupational events (41LR297, 41DT16, 41UR77, 41NA236, 41NA285, and 41SM273). 


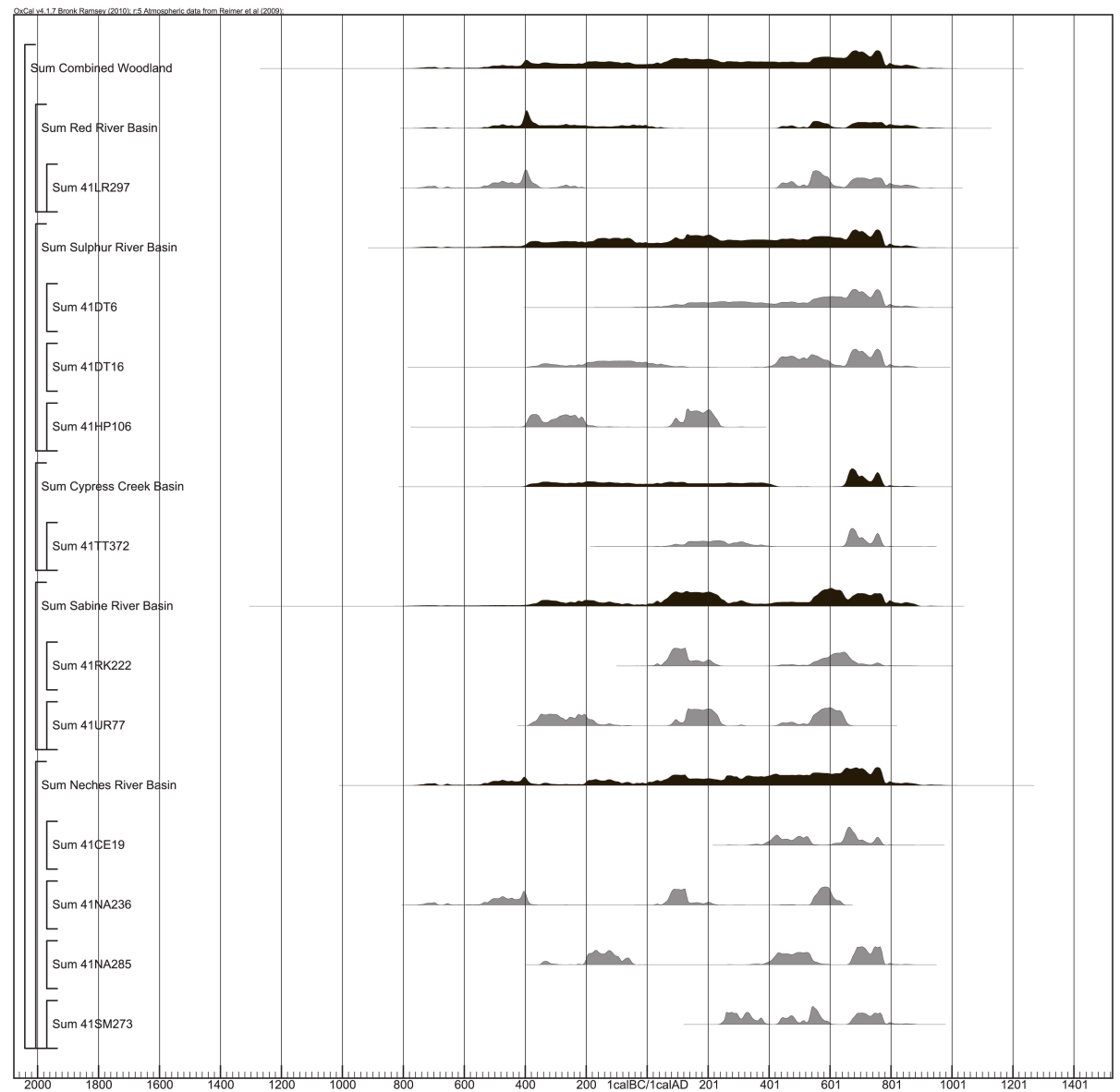

Calibrated date (calBC/caAD)

Figure 17 Summed probability distributions illustrating the impact of the 11 sites on the whole of the period, and upon the associated river basin.

Table 3 Occupations and hiatuses by river basin for sites with $4{ }^{14} \mathrm{C}$ dates. ${ }^{\text {a }}$

\begin{tabular}{llllllllr}
\hline River Basin & Site & $\mathrm{O}(1)$ & $\mathrm{H}(1)$ & $\mathrm{O}(2)$ & $\mathrm{H}(2)$ & $\mathrm{O}(3)$ & AOL & AHL \\
\hline Red & 41LR297 & 525 & 643 & 187 & 37 & 214 & 309 & 340 \\
Sulphur & 41DT6 & 831 & - & - & - & - & 831 & 0 \\
& 41DT16 & 357 & 413 & 140 & 93 & 103 & 200 & 253 \\
& 41HP106 & 150 & 287 & 196 & - & - & 173 & 287 \\
Cypress & 41TT372 & 191 & 337 & 106 & - & - & 149 & 337 \\
Sabine & 41RK222 & 167 & 218 & 333 & - & - & 250 & 218 \\
& 41UR77 & 161 & 330 & 82 & 343 & 82 & 108 & 337 \\
Neches & 41CE19 & 186 & 72 & 157 & - & - & 172 & 72 \\
& 41NA236 & 353 & 436 & 158 & 327 & 95 & 202 & 382 \\
& 41NA285 & 90 & 532 & 109 & 151 & 85 & 95 & 342 \\
& 41SM273 & 87 & 98 & 132 & 111 & 86 & 102 & 105 \\
\hline
\end{tabular}

${ }^{\mathrm{a}} \mathrm{O}=$ occupation; $\mathrm{H}=$ hiatus; $\mathrm{AOL}=$ average occupation length; $\mathrm{AHL}=$ average hiatus length. 


\section{Spatial Considerations}

It has become increasingly apparent that there was no preference for river basin or natural region by this prehistoric population as they began to intensify upon the landscape within the Post Oak Savannah, Blackland Prairie, and Pineywoods of east Texas. In fact, Woodland period populations settled in all 3 natural regions within the Red, Sulphur, Cypress Creek, Sabine, and Neches River basins. While the great majority of Woodland sites fall within the Austroriparian biotic province (Blair 1950:98), some sites - those in the western Red River and Sulphur River basins - occur within the Texan biotic province. The western boundary of the Austroriparian is limited by moisture (Blair 1950:99), and rainfall amounts range from 44 inches on the western margin of the province to 56 inches on the eastern border of Texas (Window on State Government 2012). While this region boasts the highest annual rainfall for the state, it lies within the Region of Summer Drought as characteristically defined by Carr (1967:17), where he notes that,

"[o]ne abnormal climatologic occurrence which would have deleterious effects on East Texas would be the loss in April and May of the generous rainfalls which occur there during these months and again in November and December. These are the two peak rainfall periods before and after the summer-drought months. The loss of peak rainfalls during these months could result in a year-long drought—not merely a summer drought."

This cyclical pattern produces a winter surplus and summer deficiency of water for the region (see Carr 1967: Figure 7), and may be a factor in the geographic location of Woodland-period settlements. While impossible to determine from the record of ${ }^{14} \mathrm{C}$ dates alone, shifts in residential strategies of these semi-nomadic to semi-sedentary populations may have much to do with the variability in rainfall, since seasonal shortcomings could have caused a dramatic shift in the availability of regionally important ecological resources.

Another consideration of residential strategies is trade. This is defined by Perttula and Bruseth (1990:95) as "the movement of objects or materials to be used in the production of objects back and forth between different groups." Archaeologically, participation in extra-local trade follows - virtually entirely $-500 \mathrm{BC}$ and continues to mature through the entirety of the Woodland period before fluorescing during the Caddo period in east Texas ( 800-1680) (Perttula and Bruseth 1990).

Through the analysis of median dates by way of kernel density and hierarchical cluster analysis, Woodland period median dates were found to encompass 3 potential divisions (Figure 18). Although the small sample size prevents these results from achieving the appropriate level of significance750 by Michczyńska and Pazdur (2004) and 500 by Williams (2012) - they do warrant mention here.

These temporal trends were manifest within the geographic boundaries for east Texas Woodland populations of the Fourche Maline (Schambach 1998, 2002), Mill Creek (Perttula and Nelson 2004), and Mossy Grove (Story 1990) culture areas, and appear to support Schambach's (1998:128) hypothesis that the Caddo culture developed "in situ in the Trans-Mississippi South." However, this observation appears true for all 3 currently defined culture areas in east Texas and is not limited to the Fourche Maline.

The demonstrated occupational episodes represent the cultural antecedents of the later prehistoric and protohistoric Caddo populations ( AD 800-1680) and the shift from a hunter-gatherer and horticultural economy to one dominated by agriculture within greater east Texas. While lacking in detailed temporal correlations with the material culture of the different Woodland culture areas, the 11 sites surveyed within this study illustrate a significant increase in site use during the period of AD 400-800. 


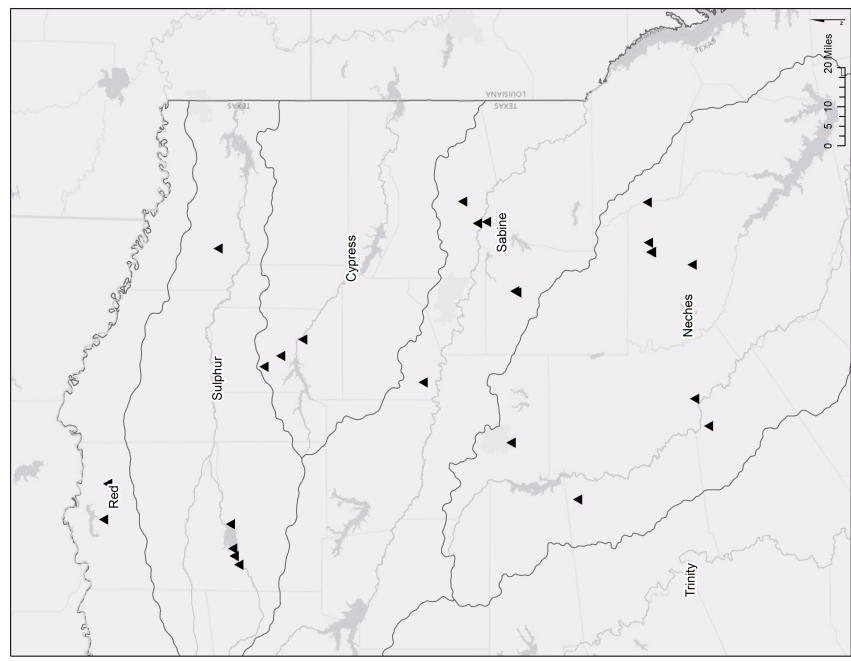

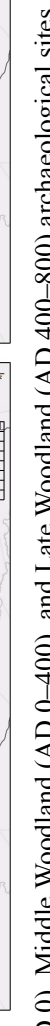
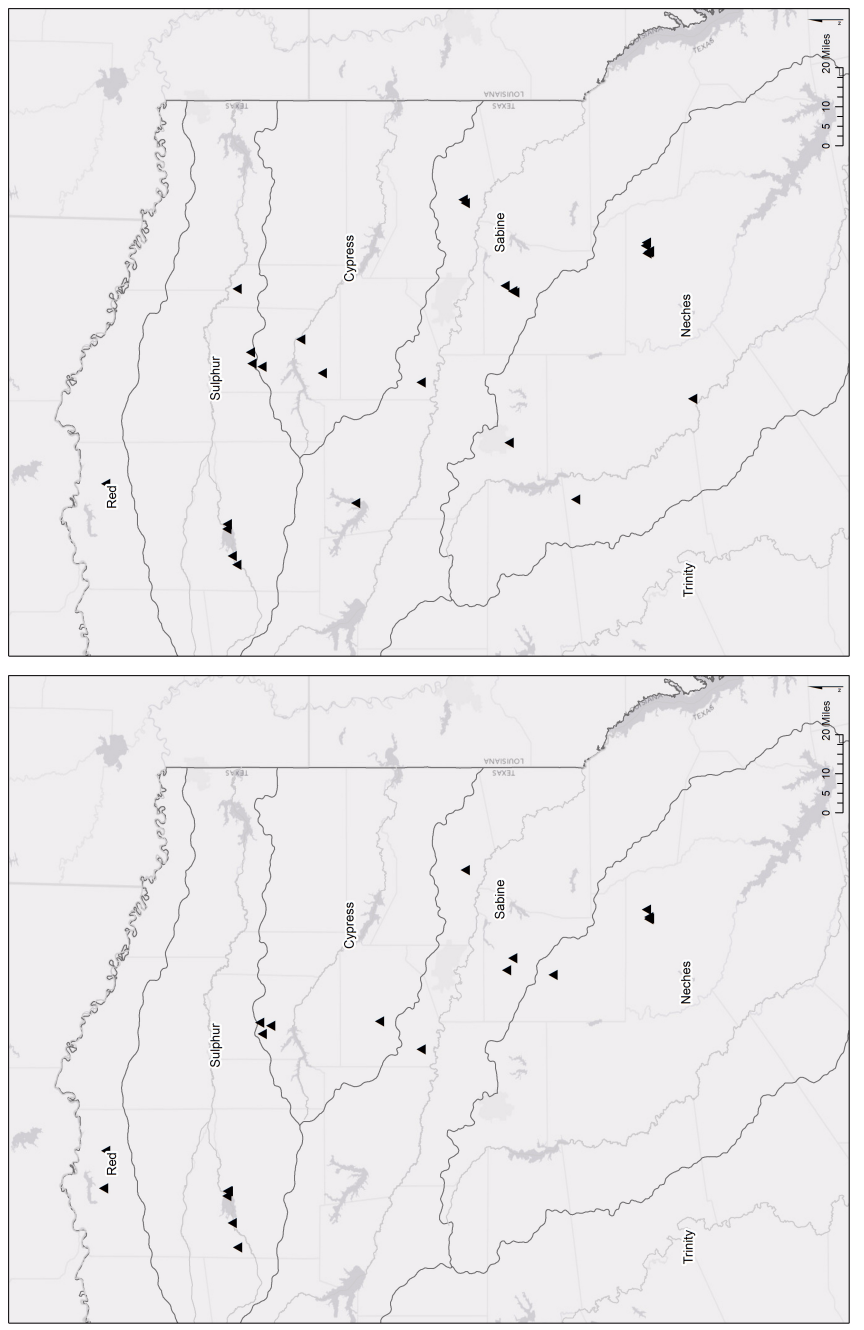

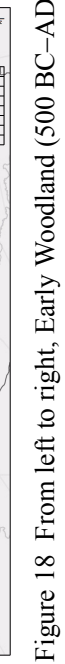


The temporal distribution of occupational episodes for Woodland sites in east Texas (see Figure 17) increased exponentially after AD 400 and the associated hiatuses decreased in both frequency and duration. Prior to AD 400, only 13 occupational episodes occurred throughout an $800 \mathrm{cal}{ }^{14} \mathrm{C} \mathrm{yr}$ period, while the number of occupational episodes increased to 16 during the last $400 \mathrm{cal}{ }^{14} \mathrm{C} \mathrm{yr}$ of the Woodland period. This trend is indicative not only of a larger population, but possibly a more sedentary lifestyle, which may temporally demonstrate the cultural shift from hunter-gatherer to agriculturalist.

\section{DISCUSSION}

Due to depositional and contextual issues and the wide variety of mitigation strategies and research designs employed throughout the region, the western boundary of the Eastern Woodlands remains one of the least well-known and explored periods in the greater Southeast. This can be seen plainly when the number of components from Woodland period sites is contrast against the much more robust representation of ${ }^{14} \mathrm{C}$ dates from the Caddo period. The fact that only 127 of the $1248{ }^{14} \mathrm{C}$ samples in the East Texas Radiocarbon Database are representative of this period speaks to the need for further research.

These results present a significant advancement in the manner by which ${ }^{14} \mathrm{C}$ assays may be manipulated for use within summed probability distributions. At the regional and sometimes local scale, most archaeologists have encountered at least 1 very well-dated site. These sites, while often incredibly informative at the microscale, are fairly detrimental to macrolevel analyses due to the amount of bias they introduce. Through incorporation of date combination to studies of summed probability distribution, the amount of site-specific sample bias can be reduced.

Although not essential to this analysis due to sample size, consideration should be given to taphonomic loss (see Surovell and Brantingham 2007; Surovell et al. 2009; Peros et al. 2010) and landuse patterns (see Grove 2008, 2009, 2011) once the sample size threshold is surpassed. When coupled with the method of date combination, these tools can further clarify much of the ambiguity encountered as we continue to move forward with our analyses of these data at the regional scale.

\section{SUMMARY AND CONCLUSION}

Regionally, statistical nuances within the data appear to illustrate the likelihood of 3 temporal divisions and an increase in occupational episodes post $\sim \mathrm{AD} 400$. While more research needs to be completed to reveal the nature of the cultural shift from hunter-gatherer/part-time horticulturist to a more agriculturalist lifestyle, this investigation illustrates those sites with temporal components that would likely be more fruitful than others within the framework of that endeavor.

Subsequent efforts to refine the chronology of the material culture from these different components should take the form of case studies from specific Woodland period sites where artifacts were recovered in association with ${ }^{14} \mathrm{C}$ samples. As that effort expands, our knowledge of the temporal and spatial distributions of specific artifact classes, types, and assemblages can be enhanced. We are quickly approaching an era where typological assignments can be associated with ${ }^{14} \mathrm{C}$ samples in this same manner, but significant advances in correlating these data with specific aspects of archaeological assemblages still need to be made as we progress in our analyses of the Woodland period of east Texas.

This analysis represents only a small sample of ${ }^{14} \mathrm{C}$ dates from the ETRD, which remains a large and understudied amalgam of ${ }^{14} \mathrm{C}$ dates that is available for use within current cultural resource manage- 
ment endeavors. Through the systematic employment of this methodological approach, it is plausible that similar analyses would strengthen the arguments presented here (i.e. shorter hiatuses during the later and better-understood Caddo period, and longer hiatuses ranging from the Archaic through Paleoindian periods), providing a productive medium through which dialogues regarding the material culture of east Texas can continue to be developed.

\section{ACKNOWLEDGMENTS}

I would like to thank Drs Timothy K Perttula, Suzanne L Eckert, Alan N Williams, James E Bruseth, Mr Ross C Fields, and an anonymous reviewer for their guidance and comments on previous drafts, Dr David L Carlson and Dr Jon C Lohse for their technical guidance, and Lauren B Selden for always expecting more. I would also like to thank Mr Ross C Fields (Prewitt \& Associates, Inc.) and Dr S Alan Skinner (AR Consultants, Inc.) for providing ${ }^{14} \mathrm{C}$ dates from their recent east Texas projects for use within this article. Lastly, the editorial staff at Radiocarbon are to be praised for their timely communication and willingness to field my numerous questions.

\section{REFERENCES}

Bamforth DB, Grund B. 2012. Radiocarbon calibration curves, summed probability distributions, and early Paleoindian population trends in North America. Journal of Archaeological Science 39(6):1768-74.

Barnhart E, Dixon B, Kotter S, Nash M, Reese-Taylor K, Skokan E, Taylor R. 1997. Data Recovery Excavations at Site 41 TT372 in the Tankersley Creek Watershed, Monticello B-2 Surface Mine, Titus County, Texas. Document No. 940608. Espey Huston \& Associates, Inc., Austin.

Bernard HR. 2006. Research Methods in Anthropology: Qualitative and Quantitative Approaches. New York: AltaMira Press.

Bever MR. 2006. Too little, too late? The radiocarbon chronology of Alaska and the peopling of the New World. American Antiquity 71(4):595-620.

Blair WF. 1950. The biotic provinces of Texas. The Texas Journal of Science 2(1):93-113.

Bronk Ramsey C. 2008. Radiocarbon dating: revolutions in understanding. Archaeometry 50(2):249-75.

Bronk Ramsey C. 2012. OxCal 4.1.7/ORAU. Electronic resource. URL: https://c14.arch.ox.ac.uk/login/login.php?Location=/oxcal/OxCal.html. Accessed January 2012.

Brewington RL, Dockall JE, Shafer HJ. 1995. Archaeology of 41MX5: A Late Prehistoric Caddoan Hamlet in Morris County, Texas. Report of Investigations No. 1. Center for Environmental Archaeology, Texas A\&M University, College Station.

Bruseth JE, Perttula TK. 1981. Prehistoric Settlement Patterns at Lake Fork Reservoir. Texas Antiquities Permit Series, Report No. 2. Austin: Texas Antiquities Committee; Dallas: Southern Methodist University.

Bruseth J, Durst J, Proctor R, Banks L, Sykes G, Pierson B. 2009. Investigations at the Gene and Ruth Ann Stallings Ranch Site (41LR297). Bulletin of the Texas Archeological Society 80:195-205.
Bryant VM, Holloway RG. 1985. A Late Quaternary paleoenvironmental record of Texas: an overview of the pollen evidence. In: Bryant VM, Holloway RG, editors. Pollen Records of Late Quaternary North American Sediments. Dallas: American Association of Stratigraphic Palynologists Foundation. p 39-70.

Carr JT. 1967. The Climate and Physiography of Texas. Report 53, Texas Water Development Board.

Clark RM. 1975. A calibration curve for radiocarbon dates. Antiquity 49(196):251-66.

Cliff MB, Sills EC, Acuna L, Dering P. 2004. Results of National Register Investigations Conducted on Site 41RK328, Rusk County, Texas. Document No. 040010. PBS\&J, Dallas.

Cooper JH, Cooper ES. 2005. Archaeological Investigations of 291 Acres at Mission Tejas State Park, Houston County, Texas. Report of Investigations No. 200406. C-Dimensions, Plano.

Corbin JE. 1984. An Archaeological Assessment of a Portion of the Washington Square Mound Site (41NA49), Nacogdoches County, Texas. Archaeological Investigations No. 1. Stephen F Austin State University, Nacogdoches.

Corbin JE, Hart JP. 1998. The Washington Square Mound Site: A Middle Caddo mound complex in south central East Texas. Bulletin of the Texas Archeological Society 69:47-78.

Corbin JE, Kisling DC, Oakes S, Hart JP. 1984. Archaeological Investigations of the Washington Square Mound Site (41NA49), Nacogdoches County, Texas. Papers in Anthropology No. 5. Stephen F. Austin State University, Nacogdoches.

Davis MW, Earls AC, Tomka MSF. 1992. 1987 Archeological Excavations at the George C. Davis Site (41CE19), Caddoan Mounds State Historical Park, Cherokee County, Texas. Technical Report No. 1. Texas Parks and Wildlife Department, Austin. 
DeWalt BR, Pelto PJ. 1985. Micro and Macro Levels of Analysis in Anthropology: Issues in Theory and Research. London: Westview Press.

Dixon B, Kotter S, Taylor R. 1997. Data Recovery Excavations at the Mockingbird Site (41TT550): The Archaic and Early Caddo Components. Document No. 970735. Espey, Huston \& Associates, Inc., Austin.

Dixon B, Smith C, Loftus S, Shipp J, Ellis L, Shortes R, Harris B, Rogers R, Wallace C, Nash M. 2009. Intensive Cultural Resources Survey of the Proposed South Henderson Deposit First 5-Year Area and Ancillary Properties, Rusk County, Texas. Document No. 080138. PBS\&J, Austin.

Dockall JE Fields RC. 2011. National Register Testing of Three Sites in the Sabine Mine's South Hallsville No. 1 Mine-Rusk Permit, Rusk County, Texas. Report of Investigations No. 162. Prewitt and Associates, Inc., Austin.

Dockall J, Katauskas S, Fields R. 2008. National Register Testing of Four Sites in the Sabine Mine's Area M, Harrison County, Texas. Report of Investigations No. 157. Prewitt and Associates, Inc., Austin.

Doehner K, Larson RE. 1978. Archaeological Research at Cooper Lake, Northeast Texas, 1974-75. Research Report No. 108. Archaeology Research Program, Southern Methodist University, Dallas.

Fields RC, Gadus EF, editors. 2012. Archeology of the Nadaco Caddo: The View from the Pine Tree Mound Site (41HS15), Harrison County, Texas. Report of Investigations No. 164. Prewitt and Associates, Inc., Austin.

Fields RC, Blake ME, Kibler KW. 1997. Synthesis of the Prehistoric and Historic Archeology of Cooper Lake, Delta and Hopkins Counties, Texas. Report of Investigations No. 104. Prewitt and Associates, Inc., Austin.

Fields RC, Gadus EF, Klement LW, Bousman CB, McLerran JB. 1993. Excavations at the Tick, Spike, Johns Creek, and Peerless Bottoms Sites, Cooper Lake Project, Delta \& Hopkins Counties, Texas. Report of Investigations No. 91. Prewitt and Associates, Inc., Austin.

Gadus EF, Fields RC, McWilliams JK, Dockall J, Wilder MC. 2006. National Register Testing of Seven Prehistoric Sites in the Sabine Mine's Area Q, Harrison County, Texas. Report of Investigations, No. 147. Prewitt and Associates, Inc., Austin.

Galan V. 1998. Excavations at 41TT653, the Ear Spool Site. CRM News \& Views 10(2):21-5. Archaeology Division, Texas Historical Commission, Austin.

Grove M. 2008 The evolution of hominin group size and land use: an archaeological perspective [unpublished $\mathrm{PhD}$ dissertation]. University of London.

Grove M. 2009. Hunter-gatherer movement patterns: causes and constraints. Journal of Anthropological Archaeology 28(2):222-33.

Grove M. 2011. A spatio-temporal kernel method for mapping changes in prehistoric land-use patterns. $\mathrm{Ar}$ chaeometry 53(5):1012-30.
Hassan FA. 1984. Radiocarbon chronology of predynastic Dagada settlements, Upper Egypt. Current Anthropology 25(5):681-3.

Hatfield V, Kibler KW, Fields RC. 2008. Interim Report on Eligibility Testing at 41TT6, 41TT846, 41TT847, 41TT851, 41TT852, 41TT853, 41TT854, 41TT858, 41TT862, 41TT865, and 41TT866, U.S. Highway 271 Mount Pleasant Relief Route, Titus County, Texas. Prewitt and Associates, Inc., Austin.

Kotter SM, Rogers R, Taylor R, Reese-Taylor K, Glander WE. 1993. Archaeological Investigations within the Monticello B-2 First Five Year Disturbance Area, Titus County, Texas. Document No. 920013. Espey, Huston \& Associates, Inc., Austin.

Kuzmin YV, Keates SG. 2005. Dates are not just data: Paleolithic settlement patterns in Siberia derived from radiocarbon records. American Antiquity 70(4):77389.

Lohse JC, with contributions by T. K. Perttula and R. A. Ricklis. 2004. Interim Report on Archaeological Testing at 41AN38 and 41AN159, Anderson County, Texas. Coastal Environments, Inc., Corpus Christi.

Mahoney R, Crawford C, Mauldin R, Nordt L, Perttula T, Reyna S. 2001. Camp Maxey III, Archaeological Testing of 23 Prehistoric Sites, Lamar County, Texas. Archaeological Survey Report No. 314. Center for Archaeological Research, The University of Texas at San Antonio.

Mahoney RB, Tomka SA, Weston J, Mauldin R. 2002. Camp Maxey IV: Archaeological Testing of Six Sites, Lamar County, Texas. Archaeological Survey Report No. 326. Center for Archaeological Research, The University of Texas at San Antonio.

Michczyńska DJ, Pazdur A. 2004. Shape analysis of cumulative probability density function of radiocarbon dates set in the study of climate change in the Late Glacial and Holocene. Radiocarbon 46(2):733-44.

Nelson B, Perttula TK. 2006a. Archaeological investigations at the Polk Estates Site (41CP245), Camp County, Texas. Journal of Northeast Texas Archaeology $24: 1-83$.

Parsons M. 1998. 41UR133: a Late Caddo hamlet at Lake Gilmer. Division of Antiquities Protection, Texas Historical Commission, Austin. Cultural Resource Management News \& Views 10(1):16-9.

Peros MC, Munoz SE, Gajewski K, Viau AE. 2010. Prehistoric demography of North America inferred from radiocarbon data. Journal of Archaeological Science 37(3):656-64.

Perttula TK. 1997. A compendium of radiocarbon and oxidizable carbon ratio dates from archaeological sites in east Texas, with a discussion of the age and dating of select components and phases. Radiocarbon 39(3): 305-42.

Perttula TK. 1998. Radiocarbon and oxidizable carbon ratio dates from archaeological sites in east Texas, part II. Journal of Northeast Texas Archaeology 11:66-90.

Perttula TK. 1999. Current archeological investigations 
at the Pilgrim's Pride Site (41CP304) in Camp County, Texas. Caddoan Archeology 10(2):7-18.

Perttula TK. 2000. Functional and stylistic analyses of ceramic vessels from mortuary features at a 15 th and 16th century Caddo site in northeast Texas. Midcontinental Journal of Archaeology 25(1):101-51.

Perttula TK, editor. 2002. Archeological Investigations at the Proposed Lake Naconiche, Nacogdoches County, Texas. Report of Investigations No. 42. Archeological and Environmental Consultants, LLC, Austin.

Perttula TK. 2008a. Analysis of the historic Caddo ceramics from 41NA223 in downtown Nacogdoches, Nacogdoches County, Texas. Journal of Northeast Texas Archaeology 28:35-50.

Perttula TK, editor. 2008b. Lake Naconiche Archeology, Nacogdoches County, Texas: Results of the Data Recovery Excavations at Five Prehistoric Archeological Sites. Report of Investigations No. 60. Archeological \& Environmental Consultants, LLC, Austin.

Perttula TK. 2010a. Recent Archeological Survey Investigations at Caddo Mounds State Historic Site (George C. Davis Site, 41CE19). Letter Report No. 242. Archeological \& Environmental Consultants, LLC, Austin.

Perttula TK. 2010b. Analysis of prehistoric artifacts from 2003 excavations at the George C. Davis Site (41CE19), Cherokee County, Texas. Journal of Northeast Texas Archaeology 33:63-7.

Perttula TK, Bruseth JE. 1990. Trade and exchange in eastern Texas, 1100 BC - A.D. 800. Louisiana Archaeology 17:93-121.

Perttula TK, Ellis LW. 2012. The Hickory Hill Site (41CP408): Archeological Investigations at a Middle Caddo Site in the Little Cypress Creek Basin in East Texas. Atkins Group, Austin.

Perttula TK, Nelson B. 2001. Archeological Test Excavations at the Prestonwood (41SM272) and Broadway (41SM273) Sites along the City of Tyler-Lake Palestine WTP Project, Smith County, Texas. Report of Investigations No. 43. Archeological and Environmental Consultants, LLC, Austin.

Perttula TK, Nelson B. 2003. The Nawi haia ina Site (41RK170): Archeological Investigations in the City of Henderson's Southside Wastewater Treatment Plant, Rusk County, Texas. Report of Investigations No. 51. Archeological \& Environmental Consultants, LLC, Austin.

Perttula TK, Nelson B. 2004. Woodland and Caddo Archeology at the Broadway or Kanduts'ah Kuhnihdahahdisa' Site (41SM273) on the City of Tyler-Lake Palestine WTP Project, Smith County, Texas. Report of Investigations No. 50. Archeological \& Environmental Consultants, LLC, Austin.

Perttula TK, Nelson B. 2006. Test Excavations at Three Caddo Sites at Mission Tejas State Park, Houston County, Texas. Report of Investigations No. 76. Archeological \& Environmental Consultants, LLC, Austin.
Perttula TK, Nelson B. 2007. Documentation of a collection of archaeological materials from the Millsey Williamson Site (41RK3), a historic Nadaco Caddo settlement. Journal of Northeast Texas Archaeology 26: $120-7$.

Perttula TK, Ricklis RA. 2005. Archeological Testing at 41 IU77 on Big Sandy Creek, Upshur County, Texas. Archeological Studies Program, Report No. 71. Texas Department of Transportation, Environmental Affairs Division, Austin.

Perttula TK, Rogers R. 2007. The evolution of a Caddo community in northeastern Texas: the Oak Hill Village Site (41RK214), Rusk County, Texas. American Antiquity 72(1):71-94.

Perttula TK, Selden Jr RS. 2011. East Texas Radiocarbon Database. Electronic resource. http://counciloftexasarcheologists.org/?page_id=27. Accessed July 2012.

Perttula TK, Sherman DL. 2009. Data Recovery Investigations at the Ear Spool Site (41TT653), Titus County, Texas. Document No. 070205. PBS\&J, Austin.

Perttula TK, Nelson B, Schniebs L. 2003. Titus Phase archeology at the S. Stockade Site (41TT865) on Tankersley Creek, Titus County, Texas. Caddoan Archeology Journal 13(1):7-15.

Perttula TK, Nelson B, Walters M, Schniebs L. 2007. Archaeological investigations of the Lang Pasture (41AN38) midden deposits on private property west of the SH 155 Right-of-Way, Anderson County, Texas. Caddo Archeology Journal 16:27-36.

Perttula TK, Kelley DB, Ricklis RA, assemblers and editors. 2011. Archeological Investigations at the Lang Pasture Site (41AN38) in the Upper Neches River Basin of East Texas. Report No. 129. Texas Department of Transportation, Archeological Studies Program, Environmental Affairs Division, Austin.

Reimer PJ, Baillie MGL, Bard E, Bayliss A, Beck JW, Blackwell PG, Bronk Ramsey C, Buck CE, Burr GS, Edwards RL, Friedrich M, Grootes PM, Guilderson TP, Hajdas I, Heaton TJ, Hogg AG, Hughen KA, Kaiser KF, Kromer B, McCormac FG, Manning SW, Reimer RW, Richards DA, Southon JR, Talamo S, Turney CSM, van der Plicht J, Weyhenmeyer CE. 2009. IntCa109 and Marine09 radiocarbon age calibration curves, 0-50,000 years cal BP. Radiocarbon 51(4): $1111-50$.

Rick JW. 1987. Dates as data: an examination of the Peruvian preceramic radiocarbon record. American Antiquity 52(1):55-73.

Rogers R, Perttula TK. 2004. The Oak Hill Village (41RK214), Rusk County, Texas. Document No. 030083. PBS\&J, Austin.

Rogers R, Nash MA, Perttula TK. 2001. Excavations at the Herman Ballew Site (41RK222), Rusk County, Texas. Document No. 000021. PBS\&J, Inc., Austin.

Schambach FF. 1998. Pre-Caddoan Cultures in the Trans-Mississippi South: A Beginning Sequence. Research Series No. 53. Arkansas Archeological Survey, Fayetteville. 
Schambach FF. 2002. Fourche Maline: a Woodland period culture of the Trans-Mississippi South. In: Anderson DG, Mainfort Jr RC, editors. The Woodland Southeast. Tuscaloosa: University of Alabama Press. p 91112.

Sherman DL. 2004. National Register Testing of Site 41CP408: A Middle Caddoan Farmstead, Camp County, Texas. Document No. 040031. PBS\&J, Austin.

Sirkin RM. 2006. Statistics for the Social Sciences. Thousand Oaks: Sage.

Story DA. 1990. Radiocarbon assays. In: Story DA, Guy JA, Burnett BA, Freeman MD, Rose JC, Steele DG, Olive BW, Reinhard KJ. The Archeology and Bioarcheology of the Gulf Coastal Plain. Research Series No. 38. Arkansas Archeological Survey, Fayetteville. p 658-735.

Straus LG, Bicho N, Winegardner AC. 2000. The Upper Palaeolithic settlement of Iberia: first generation maps. Antiquity 74(285):553-66.

Stuiver M, Reimer PJ. 1993. CALIB User's Guide Rev 3.0.3A for Macintosh computers. Quaternary Research Center, University of Washington, Seattle.

Surovell TA, Brantingham PJ. 2007. A note on the use of temporal frequency distributions in studies of prehistoric demography. Journal of Archaeological Science 34(9):1868-77.
Surovell TA, Byrd Finley J, Smith GM, Brantingham PJ, Kelley R. 2009. Correcting temporal frequency distributions for taphonomic bias. Journal of Archaeological Science 36(8):1715-24.

Taylor RE, Berger R, Dimsdale B. 1968. Electronic data processing for radiocarbon dates. American Antiquity 33(2):180-4.

Texas Natural Resources Information System. 2012. Data search and download. URL: http:// www.tnris.org/. Accessed January 2012.

Ward GK, Wilson SR. 1978. Procedures for comparing and combining radiocarbon age determinations: a critique. Archaeometry 20(1):19-31.

Webb CH, Murphey FE, Ellis WG, Green HR. 1969. The Resch Site, 41HS16, Harrison County, Texas. Bulletin of the Texas Archeological Society 40:3-106.

Wendorf F, Schild R, Haas H. 1979. A new radiocarbon chronology for prehistoric sites in Nubia. Journal of Field Archaeology 6(2):219-23.

Williams AN. 2012. The use of summed radiocarbon probability distributions in archaeology: a review of methods. Journal of Archaeological Science 39(3): 578-89.

Window on State Government. 2012. Water. Electronic resource. URL: http://www.window.state.tx.us/specialrpt/tif/water.html. Accessed July 2012. 